DR. KATHLEEN B MORRISROE (Orcid ID : 0000-0003-3840-3967)

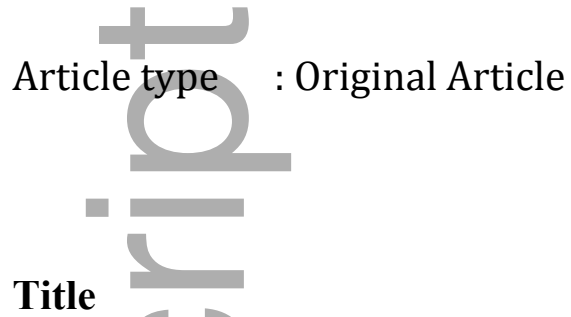

Incidence, risk factors and outcomes of cancer in systemic sclerosis

\title{
Authors
}

Kathleen Morrisroe ${ }^{1,2}$ MBBS, FRACP, PhD, Dylan Hansen² MBioStat, BBiomedSc (PharmSc), Molla Huq BSc, MSc1,2, Wendy Stevens ${ }^{2}$ MBBS, FRACP, Joanne Sahhar ${ }^{3}$ MBBS, FRACP, Gene-Siew Ngian ${ }^{3}$ MBBS, FRACP, PhD, Nava Ferdowsi ${ }^{2}$ MBBS, FRACP, MMed, Catherine Hill ${ }^{4,5,6}$ MBBS, MD, MSc, FRACP. Janet Roddy ${ }^{7}$, MBBS FRACP, Jennifer Walker ${ }^{8}, \mathrm{MBBS}$, FRACP, PhD, Susanna Proudman ${ }^{4,6}$ MBBS (Hons), FRACP, Mandana Nikpour ${ }^{1,2}$ MBBS, FRACP, FRCPA, PhD

\section{Institutional addresses}

${ }^{1}$ Department of Medicine, The University of Melbourne at St Vincent's Hospital (Melbourne), 41 Victoria Parade, Fitzroy 3065, Victoria, Australia. ${ }^{2}$ Department of Rheumatology St Vincent's Hospital (Melbourne), 41 Victoria Parade, Fitzroy 3065, Victoria, Australia. ${ }^{3}$ Department of Medicine, Monash University, Clayton and Monash Health, 246 Clayton Road, Clayton 3168 Victoria, Australia. ${ }^{4}$ Rheumatology Unit, Royal Adelaide Hospital, North Terrace, SA 5000, Australia. ${ }^{5}$ Rheumatology Unit, The Queen Elizabeth Hospital, Woodville Road, Woodville, SA 5011, Australia. ${ }^{6}$ Discipline of Medicine, University of Adelaide, SA 5000, Australia. ${ }^{7}$ Department of Rheumatology, Royal Perth Hospital, Perth, Australia. ${ }^{8}$ Rheumatology Unit, Flinders Medical Centre (Adelaide), Flinders Drive, Bedford Park 5042, South Australia, Australia.

This is the author manuscript accepted for publication and has undergone full peer review but has not been through the copyediting, typesetting, pagination and proofreading process, which may lead to differences between this version and the Version of Record. Please cite this article as doi: 10.1002/ACR.24076

This article is protected by copyright. All rights reserved 


\section{Email addresses}

Kathleen Morrisroe, kbmorrisroe@gmail.com;

Dylan Hansen, Dylan.Hansen@svha.org.au

Molla Huq, molla.huq@unimelb.edu.au;

WendyStevens, Wendy.Stevens@svha.org.au;

Joanne Sahhar, josahhar@bigpond.com;

Gene-Siew Ngian, gene-siew.ngian@mh.org.au;

Nava Ferdowsi, navaferdowsi@gmail.com;

Catherine Hill, Catherine.Hill@sa.gov.au;

Janet Roddy,Janet.Roddy@health.wa.gov.au;

Jenny Walker, Jenny.Walker@sa.gov.au;

Susanna Proudman, susanna.proudman@sa.gov.au;

Mandana Nikpour, m.nikpour@unimelb.edu.au

\section{Corresponding author}

A/Prof Mandana Nikpour, Departments of Rheumatology and Medicine, The University of Melbourne at St Vincent's Hospital (Melbourne), 41 Victoria Parade, Fitzroy 3065, Victoria, Australia; m.nikpour@unimelb.edu.au

\section{Authors' contributions}

KM: study design, data collection, data analysis, interpretation of results, preparation of manuscript. DH: data analysis, interpretation of results, preparation of manuscript. $\mathrm{MH}$ : data analysis, interpretation of results, preparation of manuscript. WS: study design, data collection, interpretation of results, preparation of manuscript. JS: data collection, interpretation of results, preparation of manuscript. GN: data collection, interpretation of results, preparation of manuscript. NF: data collection, interpretation of results, preparation of manuscript. $\mathrm{CH}$ : data collection, interpretation of results, preparation of manuscript. JR: data collection, interpretation of results, preparation of manuscript. JW: data collection, interpretation of results, preparation of manuscript. SP: data collection, 
interpretation of results, preparation of manuscript. MN: study design, data collection, data analysis, interpretation of results, preparation of manuscript.

All authors have read and approved the final manuscript.

\section{Funding}

This work was supported by Scleroderma Australia, Arthritis Australia, Actelion Australia, Bayer, CSL Biotherapies, GlaxoSmithKline Australia and Pfizer. KM was supported by Arthritis Australia and RACP DEV Star Research Establishment Fellowships. MN holds a National Health and Medical Research Council of Australia Career Development Fellowship (APP 1126370).

\section{$\underline{\text { Abstract }}$}

Objective: To quantify the burden of cancer in systemic sclerosis ( $\mathrm{SSc}$ ).

Methods: Standardized incidence ratios (SIR) and mortality ratios (SMR) relative to the general Australian population were derived. Cox proportional hazards regression was used to estimate survival in SSc patients with cancer compared to those without. Determinants of cancer were identified using logistic regression. Healthcare cost was quantified through cross-jurisicational data linkage.

Results: This SSc cohort of 1,727 had cancer incidence of $1.3 \%$ per annum and prevalence of $14.2 \%$, with SIR of 2.15 (93\%CI 1.84-2.49). The most common cancers were breast, melanoma, hematological and lung. RNAP III antibody was associated with increased risk of cancer (OR 2.9. $\mathrm{p}=0.044)$, diagnosed within five years of SSc disease

onset. Calcium channel blockers were associated with a higher risk of overall cancer (OR $1.47, \mathrm{p}=0.016$ ), breast cancer (OR 1.61, $\mathrm{p}=0.051)$ and melanoma (OR 2.01, $\mathrm{p}=0.042$ ). Interstitial lung disease (ILD) was associated with lung cancer (OR 2.83, p=0.031). Incident SSc cancer patients had more than a two-fold increased mortality compared to SSc patients without cancer [HR 2.85 (95\%CI 1.51-5.37), p=0.001). SSc cancer patients utilized more healthcare than those without cancer with an excess annual healthcare cost of AUD\$1,496 $(\mathrm{p}<0.001)$. 
Conclusion: SSc carries an increased risk of developing cancer, particularly lung cancer associated with ILD, and breast cancer and melanoma occurring close to SSc disease onset in association with RNAP III antibodies. Compared to those without cancer, SSc cancer patients had higher mortality and increased healthcare cost with an annual excess per patient cost of AUD $\$ 1,496(p<0.001)$.

\section{Significance and Innovation}

- The risk of cancer in Australian systemic sclerosis (SSc) patients is more than two fold higher than age- and sex- matched Australian population peers [standardised incidence ratio (SIR) 2.15 (93\%CI 1.84-2.49)].

- Within five years of SSc onset, there is an increased risk of breast cancer and melanoma [SIR 3.07 (95\%CI 1.47-5.64) and SIR 3.40 (95\%CI 1.10-7.93) respectively], whilst the risk of lung cancer is increased regardless disease duration [SIR 3.07 (95\% CI 1.21-3.44)].

- SSc patients with cancer have a higher all-cause mortality than the Australian population [SMR 3.13 (95\%CI 2.39-4.02)] and higher than SSc patients without cancer [SMR 2.19 (95\%CI 1.87-2.54)].

- RNAP III antibody is associated with increased risk of cancer (OR 2.9. $\mathrm{p}=0.044$ ), diagnosed within five years of SSc disease onset.

- SSc cancer patients utilize more healthcare than those without cancer, with an excess annual healthcare cost of AUD $\$ 1,496(\mathrm{p}<0.001)$.

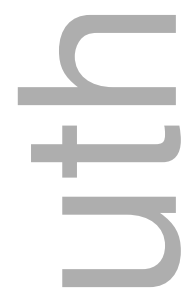

Introduction

Australia has one of the highest reported prevalences of systemic sclerosis ( $\mathrm{SSc}$ ), an autoimmune connective tissue disease characterized by vasculopathy and fibrosis [1]. Due to the progressive multi-organ nature of SSc and the lack of effective therapies, 
morbidity and mortality are high with an age- and sex-matched standardized mortality ratio (SMR) of 4.06 for newly diagnosed SSc patients and 3.39 for prevalent disease [2]. Pulmonary arterial hypertension (PAH) and interstitial lung disease (ILD), are the leading causes of SSc-related death while cancer is the leading cause of death not directly related to SSc, accounting for $38.2 \%$ of deaths [2]. With emergent therapies and improved survival in PAH and ILD, cancer is becoming an increasing concern for clinicians and patients alike.

Some series have documented an increased risk of cancer in individuals with SSc compared with the general population, in particular an increased risk of lung, breast and hematological malignancies [3-6]. This association is thought to be driven by fibrosis, chronic inflammation and B-cell stimulation, in addition to SSc-specific genetic factors, environmental factors, the use of immunosuppressive therapies and cancer driven autoimmunity, particularly in certain autoantibody profiles, [6, 7]. Identifying those individuals with SSc who are at increased risk of cancer is challenging, with conflicting results. A recent study of American SSc patients postulated that increased cancer risk may be determined by the SSc disease subtype (limited or diffuse), the SSc-specific autoantibody profile, and time since the first SSc clinical manifestation (either Raynaud or non-Raynaud) [8]. These findings are yet to be replicated in other SSc cohorts. Hence, there are no recommended cancer screening guidelines to inform clinicians caring for SSc patients, nor definitive high-risk profiles to aid in identifying those patients at heightened cancer risk. Furthermore, the financial burden associated with health service utilisation in SSc patients with cancer has not been quantified nor has the impact of cancer on the SSc patient's already reduced health related quality of life (HRQoL)[9].

Arguably, the risk of cancer is best explored through large population-based cohort studies linked with cancer registries to ensure that all diagnosed cancers and their exact location are captured accurately and reliably. These databases contain information on the utilization and associated costs of inpatient and outpatient treatment in public hospitals and ambulatory care settings [10]. Therefore, we sought to quantify the true 'burden' of cancer in Australian SSc patients by means of a data linkage study, examining its 
epidemiology, health service utilization and associated cost, in addition to its impact on HRQoL and survival.

Australia is an ideal country to evaluate the burden of cancer as all Australian states are required by law to register all cancer diagnoses to their affiliated state-based cancer registry and all citizens and permanent residents have access to public healthcare provided by a universal public health insurance scheme whose data are stored within state-based databases.

\section{Methods}

Consecutive SSc patients prospectively enrolled in the Australian Scleroderma Cohort Study (ASCS), a multi-center study of risk and prognostic factors for clinically important outcomes in SSc, were included. The ASCS database contains comprehensive demographic, disease-related and medication use data that are collected annually. Written consent was obtained from all patients at recruitment and ethical approval was obtained from all participating hospitals.

$\underline{\text { Inclusion and exclusion criteria }}$ We included all adult (>18 years) SSc patients recruited between January 2008 (ASCS cohort inception) and December 2015 (the most recent date for which cancer registry and health service utilization data are available). All patients fulfilled the American College of Rheumatology / European League Against Rheumatism Classification criteria for SSc [11].

\section{Data Linkage}

Cancer diagnosis and healthcare utilization were captured by means of data linkage. Through the Australian Institute of Heath and Welfare (AIHW), the ASCS database of de-identified SSc patients' demographic information, disease-related data, medication and HRQoL data were merged with the respective state cancer registry, hospital admission database, emergency department (ED) database, and the Medical Benefit Schedule (MBS), thereby capturing all cancer diagnoses, hospital admissions, ED 
presentations and ambulatory care use. All de-identified merged data were stored and analyzed within the Secure Unified Research Environment (SURE), which is a remoteaccess secure computing environment allowing researchers to analyze linked data.

\section{Cancer Registry data}

The ASCS dataset was linked with state based cancer registries for all cancers diagnosed to 2015 inclusive. For calculation of the standardized incidence ratio, incident cancers diagnosed between 2008-2015 were included due to the availability of Australian cancer epidemiology statistics. Each registry contains data on the type of cancer (site, morphology, grade and behavior) and cancer diagnosis year. All cancers except nonmelanoma skin cancers were included in the data analysis.

\section{Healthcare utilization}

Hospital admission and ED presentation databases contain information on the primary diagnosis and/or procedure, in addition to unique state-based variables required to estimate the financial cost to the government. The MBS lists the ambulatory care services for which a government-funded payment can be claimed [12] such as medical or allied health visits, pathology and imaging. Every MBS-listed service is assigned a 'schedule fee', an amount the government considers appropriate for the service and a 'benefit payable fee', that is approximately $75-85 \%$ of the schedule fee which the government contributes.

\section{$\underline{\text { Medication data }}$}

Medication utilization was determined from the ASCS database, wherein detailed medication use data are recorded at each visit for all patients enrolled. Extended time on therapy was defined as $\geq 2$ consecutive years on therapy or $\geq 50 \%$ of the patient's followup time if follow-up was $<2$ years.

\section{Costing methodology}

\section{Healthcare cost}


Every hospital admission and ED presentation is allocated a Diagnosis Related Grouping (DRG), an Urgency Related Grouping (URG) and an associated weighted unit, which incorporates the expected costs of investigations and medications for that condition in a hospital setting. Cost was calculated based on financial year of admission and the corresponding weighted value. Ambulatory care cost was calculated using the total MBS 'benefit payable fee', making it an accurate reflection of Australian government cost.

\section{$\underline{\text { ASCS Clinical data }}$}

Patient demographics and clinical variables were obtained from the ASCS database. Clinical manifestations and autoantibody status were defined as present if present ever from the time of SSc diagnosis. SSc disease onset was defined as the first SSc clinical manifestation. SSc skin onset was defined from first skin change. Autoantibodies are tested at enrollment and annually thereafter at St Vincent's laboratory. Antinuclear antibody (ANA) is tested for by indirect immunofluorescence, the extranuclear antibody (ENA) screened for by an enzyme linked immunosorbent assay (ELISA) and if positive, characterization is performed. PAH was diagnosed by right heart catheterization according to international criteria (defined as mean pulmonary arterial pressure (mPAP) of at least $25 \mathrm{mmHg}$ and a pulmonary arterial wedge pressure (PAWP) of $<15 \mathrm{mmHg}$ )). [13]. ILD was defined by characteristic changes on high-resolution computer tomography (HRCT) lung. All patients in the ASCS undergo annual screening for PAH and ILD using echocardiography and lung function tests. Myocardial disease was defined on endomyocardial biopsy or as the presence of conduction deficits, arrhythmia, right ventricular or left ventricular dysfunction in the absence of other causes. Gastrointestinal (GIT) involvement included any of the following: gastro-oesphageal reflux disease (GERD), reflux esophagitis, oesphageal dysmotility and/or esophageal stricture on endoscopy, intestinal dysmotility defined on barium and nuclear medicine studies, and diarrhea and/or fecal incontinence. Patient status (alive or dead) was censored in January 2016 and the cause of death, verified from hospital records and death certificate, was recorded in the database.

$\underline{\text { Statistical analysis }}$ 
Data are presented as mean \pm standard deviation (SD) for normally distributed and median (interquartile range (IQR)) for non-normally distributed continuous variables, and as number (percentage) for categorical variables. Differences in frequency were tested using chi-square and Fisher's exact tests. Standardized incidence ratios (SIR), with exact poisson $95 \%$ confidence intervals $(95 \% \mathrm{CI})$, were calculated as the ratio of cancer incidence in SSc patients to the incidence in the general Australian population weighted according to age and sex, derived from the AIHW registry of incident cancers occuring during 2008-2015 [14]. Standardized mortality ratios (SMRs) were calculated as the ratio of observed deaths in SSc patients compared with the expected death rate in the general Australian population weighted according to age and sex [14]. Univariable and multivariable logistic regression were used to determine the associations of different variables with cancer. Variables with a p-value $<0.05$ in univariable regression or variables deemed to be of clinical significance to the outcome with a p-value $<0.20$ were included in the multivariable logistic regression analysis. Further logistic regression analyses were preformed to determine the characteristics associated with early onset cancer (diagnosed within 5 years of SSc disease onset) compared with late onset cancer (diagnosed $>$ 5years from SSc onset), and also characteristics associated with cancer diagnosed within 5, 3 and 1 years from SSc onset compared with those without cancer recruited $>5,3$ and 1 year of SSc disease onset, respectively. Cox proportional hazards regression was used to estimate survival in a (i) prevalent cohort, and (ii) an incident cohort (defined as those recruited within 2 years of their disease onset) with cancer compared to those without. Kaplan-Meier (K-M) curves were used to estimate survival by cancer status. Log-rank and Wilcoxon tests were used to compare survival curves. A two-tailed $p$ yalue of 0.05 or less was considered statistically significant. All statistical analyses were performed using STATA 14.0 (StataCorp LP, College Station, TX, USA).

\section{$\underline{\text { Results }}$}

\section{Patient characteristics}

Our cohort consisted of 1,727 SSc patients contributing to 7,081 person years of followup. The majority were causcasian (92.1\%), female (85.9\%) with limited disease (lcSSc) $(73.9 \%)$ and a mean $( \pm \mathrm{SD})$ age at $\mathrm{SSc}$ onset of $46.6( \pm 14.3)$ years with mean $( \pm \mathrm{SD})$ 
disease duration at enrolment of $10.9( \pm 10.6)$ years (Table 1$)$. Of those with autoantibody data, $796(48.1 \%)$ were anticentromere (ACA) antibody positive, 249 (15.3\%) were antitoposomerase-1 (Scl-70) positive, 155 (14.0\%) were RNA Polymerase III (RNAP) antibody positive and $460(29.6 \%)$ were negative for these three autoantibodies (autoantibody negative group) (Table 1).

Consistent with other large SSc cohorts, the majority of patients experienced GIT involvement (83.7\%), nearly half experienced digital ulceration (DU) (46.5\%) and calcinosis (39.7\%), a third had ILD (28.3\%) and 12.2\% had PAH (Table 1). One quarter of the cohort had received extended immunosuppression (24.8\%). Prednisolone (PNL) was the most commonly prescribed (44.9\%), followed by methotrexate (MTX) $(21.9 \%)$, hydroxychloroquine (HCQ) (19.7\%), mycophenolate mofetil (MMF) (10.9\%) and cyclophosphamide (8.9\%). Biological disease modifying agents (bDMARDs) were rarely used $(2.3 \%)$. Of concern, $50.1 \%$ of the cohort had a current or past history of smoking (Table 1).

SSc patients with cancer had a higher all-cause mortality than the Australian population [SMR 3.13 (95\%CI 2.39-4.02)] and higher than SSc patients without cancer [SMR 2.19 (95\%CI 1.87-2.54)] (Table 3). Incident SSc cancer patients (recruited within two years of SSc disease onset) had more than a two-fold increased mortality compared to SSc patients without cancer [HR 2.85 (95\%CI 1.51-5.37), p=0.001)] (Figure 1). In those with cancer, the primary cause of death was non-SSc related in $58.1 \%$, most commonly due to their cancer (77.1\%), followed by ischemic heart disease (IHD) (5.7\%) and sepsis (5.7\%). In SSc patients without cancer, the primary cause of death was SSc-related in $69.5 \%$, most commonly due to PAH (47.0\%), ILD (19.7\%) or a combination of PAH and ILD $(17.1 \%)$.

\section{Patient characteristics by cancer status}

Cancer was diagnosed in $14.2 \%$ of our cohort, with 43 individuals having more than one cancer type (Table 2). Our cohort had a higher incidence of cancer than the Australian population [SIR 2.15 (95\%CI 1.84-2.49)], with an increased SIR for early cancer 
diagnosed within 5 years of SSc disease onset [SIR 2.52 (95\% CI 1.82-3.44)] (Table 3). Specific cancer types with a higher incidence than the background population included early breast cancer [SIR 3.07 (95\%CI 1.47-5.64)], lung cancer [SIR 3.07 (95\%CI 1.213.44)] and early melanoma [SIR 3.40 (95\%CI 1.10-7.93)] (Table 3).

The mean $( \pm \mathrm{SD})$ age at cancer diagnosis was $57.7( \pm 12.9)$ years with a mean SSc disease duration of 8.1 $( \pm 14.7)$ years (Table 1). Those who developed cancer were older at the onset of SSe $[49.9( \pm 14.3)$ vs $46.0( \pm 14.3)$ years, $\mathrm{p}=0.001]$, more likely to be Caucasian ( $95.8 \%$ vs $91.5 \%, \mathrm{p}=0.023)$, have PAH ( $17.9 \%$ vs $11.2 \%$, $\mathrm{p}=0.003)$, mild ILD ( $35.1 \%$ vs $27.2 \%, \mathrm{p}=0.011)$ and have had extended treatment with a calcium channel blocker (CCB) $(46.1 \%$ vs $34.6 \%, p<0.001)$ than those without cancer. Cancer patients were more likely to have been treated with cyclophosphamide ( $13.1 \%$ vs $8.2 \%, \mathrm{p}=0.012)$. Rituximab was more commonly used in cancer patients post their cancer diagnosis; none received it prior to their cancer diagnosis (Table 1). Factors associated with cancer in SSc in univariable logistic regression are summarized in Supplementary Table 1. In multivariable logistic regression, increasing age at SSc onset (OR 1.02, $\mathrm{p}=0.001$ ), the presence of ILD (OR $1.46, \mathrm{p}=0.017)$, PAH (OR1.53,p=0.021) and RNAP III antibody (OR 1.47, $\mathrm{p}=0.016$ ) were associated with cancer (Table 4). Cancer occurred independently of traditional risk factors such as smoking history and immunosuppressive medications.

Temporal association between cancer onset and SSc onset in those with cancer In multivariable logistic regression, SSc patients with early onset cancer (diagnosed within 5 years of SSc onset) were more likely to be older at SSc onset (OR1.05, $\mathrm{p}=0.004$ ), less likely to have DU (OR $0.43, \mathrm{p}=0.042$ ) and more likely to be RNAP positive (OR 2.91, $\mathrm{p}=0.044$ ) compared with those with cancer diagnosed more than five years from disease onset (Table 4). Univariable logistic regression analyses are summarized in Supplementary Table 1.

Temporal association between cancer and SSc onset in those with and without cancer SSc patients with early onset cancer (diagnosed $<5$ years from disease onset) compared to SSc patients without cancer ( $>5$ years from disease onset) were older at SSc onset (OR 
$1.05, \mathrm{p}<0.001$ ), less likely to have DU (OR 0.44, $\mathrm{p}=0.018$ ) and more likely to be RNAP positive (OR 2.14, $\mathrm{p}=0.043$ ). Univariable logistic regression analyses are summarized in Supplementary Table 1 . These variables maintained significance when assessing a closer temporal association (defined at 3 years and 12 months from disease onset) (Supplemetary Table 2 and 3 ).

\section{Cancer details}

Breast eancer (30.2\%), followed by melanoma (18.5\%), hematological malignancies (13.5\%), female reproductive tract malignancies (13.5\%), and lung cancer $(10.2 \%)$, were the five most common cancers in our cohort (Table 2).

\section{Breast Cancer}

Breast cancer, occurring with a prevalence of $4.3 \%$ in our cohort ( 74 primary breast), did not have an increased SIR compared with the Australian population [SIR 1.51 (95\% CI 0.98-2.21)]. However, early breast cancer did [SIR 3.07 (95\%CI 1.47-5.64)]. Factors associated with early and overall breast cancer determined by univariable logistic regression analysis are summarized in Supplementary Tables 4 and 5. In multivariable logistic regression, age at SSc onset (OR 1.07, $\mathrm{p}<0.001$ and the presence of RNAP antibody (OR 4.28,p=0.018) were associated with an increased risk of early breast cancer. Increasing age at SSc onset (OR1.03, $\mathrm{p}=0.005)$ and GIT mainfestations (OR 2.99, $\mathrm{p}=0.036$ ) were associated with an increased risk of overall breast cancer, while pregnancy history (OR 0.66, $\mathrm{p}=0.041$ ) was protective (Table 5). The association between extended use of $\mathrm{CCB}$ and increased risk of overall breast malignancy narrowly missed statistical significance with an OR 1.61, $\mathrm{p}=0.051$.

\section{Melanoma skin cancer}

Melanoma, occurring with a prevalence of $2.1 \%$ in our cohort (37 patients), did not have an increased SIR compared with the Australian population [SIR 1.30 (95\% CI 0.592.46)]. However, early melanoma did [SIR 3.40 (95\%CI 1.10-7.93)]. Supplementary Table 4 summarizes factors associated with melanoma by univariable logistic regression. In multivariable logistic regression, the use of $\mathrm{CCB}$ was associated with an increased risk 
of melanoma (OR 2.01,p=0.042) (Table 5), while increasing age at SSc onset was associated with increased risk of early melanoma (Table 5). There was no significant association between melanoma and smoking or use of immunosuppression (Supplementary Table 4, Table 5).

\section{Hematological Malignancies}

Hematological malignancies occurred with a prevalence of $1.9 \%$ (32 primary hematological malignancies). All patients were Caucasian. Factors associated with hematological malignancies in SSc determined by univariable logistic regression analysis are summarized in Supplementary Table 4. In multivariable logistic regression, increasing age at SSc onset (OR 1.04, $\mathrm{p}=0.007)$ was associated with haematological malignancies, while the absence of a SSc-specific anitbodiy was protective (OR 0.35 , $\mathrm{p}=0.05)$. A SIR for overall haematological malignancies in addition to lymphoma and leukaemia was calculated (Table 3). There was no increased incidence of haematological malignancies in our cohort.

\section{Lung Cancer}

Lung cancer, occurring with a prevalence of $1.5 \%$ (25 primary lung cancers), had an increased incidence compared with the Australian population [SIR 2.12 (95\%CI 1.213.44)]. The SIR was even higher for those diagnosed with late lung cancer (occurring $>$ 5years from disease onset) [SIR 2.51 (95\%CI 1.34-4.29)] (Table 3). Factors associated with lung cancer in univariable logistic regression analysis are summarized in Supplementary Table 4. In multivariable logistic regression, the presence of ILD (OR $2.83, \mathrm{p}=0.031)$ was associated with lung cancer, while the presence of ACA was protective (OR 0.22, $\mathrm{p}=0.023$ ) (Table 5). The risk of lung cancer was independent of traditional risk factors such as smoking and immunosuppressive therapies.

\section{Healthcare utilization and associated cost}

Cancer patients were admitted to hospital more frequently and utilized more ambulatory care services then those without cancer but there was no difference in the frequency of ED presentations (Table 6). On average, the total annual healthcare cost in those with 
cancer was AUD\$8,816(6,401-12,308) per person, composed of hospital cost AUD \$4,196.6 (2,676-6,489), ED cost AUD\$443 (0-866) and ambulatory care cost of AUD $\$ 3,164$ (2,173-5,825). This was significantly higher than those without cancer who had a annual healthcare cost of AUD\$7,320 (5,076-10,368) per person, composed of hospital cost AUD $\$ 3,776(2,291-5,928)$, ED cost AUD $\$ 422$ (0-746) and ambulatory care cost AUD\$2,319 (1,380-3,502) (Table 6).

\section{HRQoL}

Our SSc cohort reported lower HRQoL than the general population particularly in the physical component score (PCS) of the SF-36 (Table 1). Cancer patients had a even lower PCS of the SF-36 those without cancer (53.5 vs 38.7, p<0.001) (Table 1).

\section{Discussion}

This large well-characterized study investigates the epidemiology and determinants of cancer in SSc patients prospectively enrolled in a SSc cohort database linked to Australian cancer registry databases. In our cohort of 1,727 SSc patients, the cancer incidence and prevalence of $1.3 \%$ and $14.2 \%$ respectively, is consistent with previously reported incidence (1.4\%) and prevalence (4\%-22\%) [4]. SSc patients have an increased risk of cancer compared with age- and sex-matched population peers [SIR $2.15(93 \% \mathrm{CI}$ 1.84-2.49)], especially for lung cancer [SIR 2.12 (95\%CI 1.21-3.44)], early breast cancer [SIR 3.07 (95\%CI 1.47-5.64)] and early melanoma [SIR 3.40 (95\%CI 1.10-7.93)] occurring independently of traditional cancer risk factors (eg. smoking and immunosuppressive therapy). Moreover, SSc cancer patients have a higher all-cause mortality that those without cancer [SMR 3.13 (95\%CI 2.39-4.02) vs SMR 2.19 (95\%CI 1.87-2.54)] while incident SSc cancer patients have more than a two-fold increased mortality rate compared to non-cancer patients [HR 2.85 (95\%CI 1.51-5.37), $\mathrm{p}=0.001)$ ]. From an economic perspective, SSc cancer patients utilized more healthcare than those without cancer, with an annual excess healthcare cost per patient of AUD $\$ 1,496$ $(\mathrm{p}<0.001)$. 
Our epidemiological findings are consistent with the results of recent meta-analyses evaluating cancer risk in SSc $[4,5,15]$, all showing an increased cancer risk in SSc. Consistent with the literature [15], we found an increased SIR for lung and early breast cancer, but not for liver and bladder cancer given the low number of these cancers in our cohort ( 2 and 1 respectively) [15]. Interestingly, we found an increased SIR for early cancers in our cohort, occurring within five years of SSc disease onset, which is consistent with the cancer induced autoimmunity hypothesis proposed in the literature, $[16,17]$ with studies showing a close temporal association between cancer diagnosis and SSc onset, with one study reporting a SIR for cancer within twelve months of SSc onset of 2.79 compared with more than twelve months from SSc onset of 1.40 [15].

Within our cohort, increasing age at SSc onset, the presence of ILD, PAH and extended use of CCB were associated with the development of overall cancers, independently of the temporal association of cancer diagnosis with SSc disease onset. The biphasic cancer incidence in SSc reported in the literature is interesting, with an increased cancer incidence at SSc onset, postulated to be a paraneoplastic phenomenon [16, 17], and a second peak in incidence after 6-8 years of disease duration [7]. We found that increased age at SSe onset, the presence of RNAP positivity and lack of DU were associated with the development of early onset cancers (diagnosed $<5$ years from SSc onset) compared with those who had late onset cancer ( $>5$ years from SSc onset). These variables were also associated with the development of early onset cancer compared with patients without cancer and disease duration of $>5$ years. The association between the presence of RNAP and early onset cancer has been described in the literature $[8,18]$ and suggests that its presence should alert the treating clinician to an increased cancer risk phenotype concurrent with SSc onset, thus ensuring that the patients undergo their age-appropriate cancer screening. Furthermore, the potential role of SSc-specific autoantibodies in profiling cancer risk phenotypes in SSc is further highlighted in our study in those with lung cancer and haematological malignancies wherein the presence of ACA is protective for lung cancer (OR 0.22, p=0.031), while the lack of any SSc-specific autoantobodies was protective for haematological malignancy (OR $0.35, \mathrm{p}=0.005$ ). 
Breast cancer was the most commonly diagnosed cancer in our cohort, occurring with a prevalence of $4.3 \%$. The overall SIR for breast cancer in our cohort was not increased, however when assessing early breast cancer (occurring within five years of SSc onset), the SIR was increased compared with Australian breast cancer incidence [SIR 3.07 $(95 \% \mathrm{CI} 1.47-5.64)]$ adding to the growing literature regarding the temporal association between SSc onset and breast cancer diagnosis [19].

The association between the extended use of CCB and overall cancer (OR 1.46, $\mathrm{p}=0.016)$, breast cancer $(\mathrm{OR} 1.61, \mathrm{p}=0.051)$ and melanoma $(\mathrm{OR} 2.01, \mathrm{p}=0.042)$ in our cohort was unexpected, but has been reported in the literature with conflicting results [2022]. This association is hypothesized to be related to the role of calcium in cell apoptosis, such as activation of the caspase pathway, induction of endonuclease activity and mitochondrial permeation. By modifying the intracellular calcium level, CCBs can indirectly affect these regulatory pathways, impairing cell apoptosis promoting the development of malignancies. As due to its prevalent nature, correction for disease duration in our cohort was not possible, it is not clear whether this association reflects cancer occurrence in longstanding SSc or is related to chronic CCB use. Given the worldwide prevalent use of CCB, population-based cancer, prescription and healthregistries research is under way to resolve this contentious area.

Healthcare utilization attributable to cancer accounts for a substantial proportion of healthcare expenditure in Australia, accounting for an estimated AUD\$4.5billion in 2009 and $4 \%$ of all government expenditure in health [23]. A recent Australian study estimated the direct cost of cancer care to the Australian government, including hospitalizations, ED visits, ambulatory care and pharmaceutical therapy, in 2013 to be AUD\$6.5billion for cancer patients who survived five years post cancer diagnosis, equating to a mean annual excess cost of AUD\$2,500 per cancer patient [24]. Our study found an annual excess total healthcare utilisation cost of AUD\$1,496 per SSc patients with cancer. This cost is inclusive of hospital admission, ED presentation and ambulatory care, but is exclusive of medication cost which is likely to be substantial given the currently available cancer therapies. The high costs associated with SSc cancer patients highlights the complexity of 
care required for those with an underlying multisystem condition, such as SSc, who need close and frequent monitoring, with a multidisciplinary approach to care, even in the absence of cancer. Despite cancer being associated with significantly reduced HRQoL, particularly in physical functioning and role physical domains of the SF-36 [25], there was no difference in these domains in our cohort among those with and without cancer. This may be becasue SSc patients report significantly reduced HRQoL due to SSc itself, even in absence of cancer [9].

Strengths of our study include its methodology of linking a large population-based clinical database with state-based cancer registries enabling a high degree of case ascertainment, accuracy and reliability of results. Limitations of our study include low patient numbers in some cancer types limiting further analysis particularly in our incident SSc cancer cohort $(n=53)$ which did not enable us to reliably determine factors associated with cancer in this specific cohort. Additionally, as HRCTs were only preformed in those patients with a clinical suspicion of ILD or abnormal RFT, there is the potential for selection bias and over-diagnosis of lung cancers in those that underwent a HRCT compared with those that did not undergo a HRCT.

\section{Conclusion}

Through a data linkage study combining a large SSc clinical database with cancer registries, we found that Australian SSc patients have an increased risk of cancer compared with age- and sex-matched population peers [SIR 2.15 (93\%CI 1.84-2.49)], occurring independently of traditional cancer risk factors. Those with incident cancer have a two-fold increased all-cause mortality compared to non-cancer patients [HR 2.85 (95\%CI 1.51-5.37), $\mathrm{p}=0.001)]$. We highlight the economic burden associated with cancer in a complex multisystem disease and stress the potential role of SSc-specific autoantibodies in profiling cancer risk phenotypes in SSc.

\section{$\underline{\text { References }}$}


1. Chifflot H, Fautrel B, Sordet C, Chatelus E, Sibilia J: Incidence and Prevalence of Systemic Sclerosis: A Systematic Literature Review. Seminars in Arthritis and Rheumatism 2008, 37(4):223-235.

2. Hao Y, Hudson M, Baron M, Carreira P, Stevens W, Rabusa C, Tatibouet S, Carmona L, Joven BE, Huq M et al: Early Mortality in a Multinational Systemic Sclerosis Inception Cohort. Arthritis Rheumatol 2017, 69(5):10671077.

3. Onishi A, Sugiyama D, Kumagai S, Morinobu A: Cancer incidence in systemic sclerosis: Meta-analysis of population-based cohort studies. Arthritis and Rheumatism 2013, 65(7):1913-1921.

4. T. Nevskaya SC, A. Roos, C. Pasarikovski, A. Kron, C. Chau and S. Johnson: Epidemiology of Cancer in Systemic Sclerosis-Systematic Review and Meta-Analysis of Cancer Incidence, Predictors and Mortality. Open Journal of Rheumatology and Autoimmune Diseases 2013,, 3 (4):231-245.

5. Bonifazi M, Tramacere I, Pomponio G, Gabrielli B, Avvedimento EV, La Vecchia C, Negri E, Gabrielli A: Systemic sclerosis (scleroderma) and cancer risk: systematic review and meta-analysis of observational studies. Rheumatology (Oxford) 2013, 52(1):143-154.

6. Zeineddine N, Khoury LE, Mosak J: Systemic Sclerosis and Malignancy: A Review of Current Data. Journal of clinical medicine research 2016, 8(9):625632.

7. Yu KH, Kuo CF, Huang LH, Huang WK, See LC: Cancer Risk in Patients With Inflammatory Systemic Autoimmune Rheumatic Diseases: A Nationwide Population-Based Dynamic Cohort Study in Taiwan. Medicine 2016, 95(18):e3540.

8. Igusa T, Hummers LK, Visvanathan K, Richardson C, Wigley FM, CasciolaRosen L, Rosen A, Shah AA: Autoantibodies and scleroderma phenotype define subgroups at high-risk and low-risk for cancer. Ann Rheum Dis 2018.

9. Morrisroe K, Hudson M, Baron M, de Vries-Bouwstra J, Carreira PE, Wuttge DM, Wang M, Frech TM, Stevens W, Proudman SM et al: Determinants of 
health-related quality of life in a multinational systemic sclerosis inception cohort. Clinical and experimental rheumatology 2018.

10. Australias health 2016, http://www.aihw.gov.au/australias-health/2016/healthsystem/ (accessed March 2017).

11. Van den Hoogen F, Khanna D, Fransen J, Johnson SR, Baron M, Tyndall A, Matucci-Cerinic M, Naden RP, Medsger TA, Jr., Carreira PE et al: 2013 classification criteria for systemic sclerosis: an American college of rheumatology/European league against rheumatism collaborative initiative. Ann Rheum Dis 2013, 72(11):1747-1755.

12. Specialist clinics in Victorian Public Hospitals: A resource kit for MBS-biled services http://www.health.vic.gov.au/divisions/hhsp/fundin (accessed 23/2/2017).

13. Galie N, Humbert M, Vachiery JL, Gibbs S, Lang I, Torbicki A, Simonneau G, Peacock A, Vonk Noordegraaf A, Beghetti M et al: [2015 ESC/ERS Guidelines for the diagnosis and treatment of pulmonary hypertension]. Kardiologia polska 2015, 73(12):1127-1206.

14. Australian Institute of Health and Welfare 2017. Cancer in Australia 2017. Cancer series no.101. Cat. no. CAN 100. Canberra: AIHW.

15. Onishi A, Sugiyama D, Kumagai S, Morinobu A: Cancer incidence in systemic sclerosis: meta-analysis of population-based cohort studies. Arthritis and rheumatism 2013, 65(7):1913-1921.

16. Shah AA, Casciola-Rosen L: Cancer and scleroderma: a paraneoplastic disease with implications for malignancy screening. Current opinion in rheumatology 2015, 27(6):563-570.

17. Shah AA, Rosen A: Cancer and systemic sclerosis: novel insights into pathogenesis and clinical implications. Current opinion in rheumatology 2011, 23(6):530-535.

18. Shah AA, Hummers LK, Casciola-Rosen L, Visvanathan K, Rosen A, Wigley FM: Examination of autoantibody status and clinical features associated with cancer risk and cancer-associated scleroderma. Arthritis \& rheumatology (Hoboken, NJ) 2015, 67(4):1053-1061. 
19. Colaci M, Giuggioli D, Vacchi C, Lumetti F, Iachetta F, Marcheselli L, Federico M, Ferri C: Breast cancer in systemic sclerosis: results of a cross-linkage of an Italian Rheumatologic Center and a population-based Cancer Registry and review of the literature. Autoimmunity reviews 2014, 13(2):132-137.

20. Wright CM, Moorin RE, Chowdhury EK, Stricker BH, Reid CM, Saunders CM, Hughes JD: Calcium channel blockers and breast cancer incidence: An

updated systematic review and meta-analysis of the evidence. Cancer epidemiology 2017, 50(Pt A):113-124.

21. Li CI, Daling JR, Tang MT, Haugen KL, Porter PL, Malone KE: Use of antihypertensive medications and breast cancer risk among women aged 55 to 74 years. JAMA internal medicine 2013, 173(17):1629-1637.

22. Gandini S, Palli D, Spadola G, Bendinelli B, Cocorocchio E, Stanganelli I, Miligi L, Masala G, Caini S: Anti-hypertensive drugs and skin cancer risk: a review of the literature and meta-analysis. Critical reviews in oncology/hematology 2018, 122:1-9.

23. AIHW. Health system expenditure on cancer and other neoplasms in Australia: 2008 \pm 09 . Cancer series no. 81. Australian Institute of Health and Welfare. Canberra, Australia; 2013.

24. Goldsbury DE, Yap S, Weber MF, Veerman L, Rankin N, Banks E, Canfell K, O'Connell DL: Health services costs for cancer care in Australia: Estimates from the 45 and Up Study. PLoS One 2018, 13(7):e0201552.

25. Boini S, Briançon S, Guillemin F, Galan P, Hercberg S: Impact of cancer occurrence on health-related quality of life: A longitudinal pre-post assessment. Health and Quality of Life Outcomes 2004, 2(1):4. 
Table 1. Patient characteristics $(n=1,727)$

\begin{tabular}{|c|c|c|c|c|}
\hline \multirow[t]{3}{*}{ Patient characteristics } & SSc patients & $\begin{array}{l}\text { SSc patients } \\
\text { with cancer }\end{array}$ & $\begin{array}{c}\text { SSc patients } \\
\text { without cancer }\end{array}$ & \multirow{3}{*}{ p value } \\
\hline & $\mathrm{n}=\mathbf{1 , 7 2 7}$ & $n=245(14.2 \%)$ & $\mathrm{n}=1,482(85.8 \%)$ & \\
\hline & $\begin{array}{c}\text { mean } \pm \text { SD } \\
\text { or } \%\end{array}$ & $\begin{array}{c}\text { mean } \pm \text { SD or } \\
\%\end{array}$ & mean \pm SD or $\%$ & \\
\hline \multicolumn{5}{|l|}{ Demographics } \\
\hline Female & $1,483(85.9 \%)$ & $210(85.7 \%)$ & $1,273(85.8 \%)$ & 0.939 \\
\hline Caucasian ethnicity & $1,509(92.1 \%)$ & $226(95.8 \%)$ & $1,283(91.5 \%)$ & 0.023 \\
\hline Age at SSc onset*, years & $46.6(14.3)$ & $49.9(14.3)$ & $46.0(14.3)$ & 0.001 \\
\hline Age at onset of SSc skin involvement, years & $48.5(14.2)$ & $52.5(14.4)$ & $47.8(14.2)$ & 0.001 \\
\hline SSc disease duration $* *$ at recruitment, years & $10.9(10.6)$ & $13.7(12.6)$ & $10.5(10.2)$ & $<0.001$ \\
\hline Follow-up since recruitment, years & $4.1(3.4)$ & $4.3(3.4)$ & $4.1(3.4)$ & 0.452 \\
\hline Limited SSc & $1,266(73.9 \%)$ & $184(75.7 \%)$ & $1,082(73.6 \%)$ & 0.477 \\
\hline Smoking history (current or ever) & $856(50.1 \%)$ & $126(52.7 \%)$ & $730(49.8 \%)$ & 0.513 \\
\hline Pregnancy history & $941(63.5 \%)$ & $139(66.2 \%)$ & $802(63.0 \%)$ & 0.374 \\
\hline Age at cancer diagnosis & - & $57.7(12.9)$ & $47.8(14.2)$ & 0.001 \\
\hline Disease duration at cancer diagnosis & - & $8.1(14.7)$ & - & - \\
\hline Alive at end of follow-up & $1,460(84.5 \%)$ & $178(72.7 \%)$ & $1,282(86.5 \%)$ & $<0.001$ \\
\hline
\end{tabular}




\begin{tabular}{|c|c|c|c|c|}
\hline \multicolumn{5}{|l|}{ Scleroderma-specific antibodies ${ }^{* * * *}$} \\
\hline $\operatorname{ACA}(n=1,656)$ & $796(48.1 \%)$ & $107(44.9 \%)$ & $689(48.6 \%)$ & 0.299 \\
\hline $\operatorname{Scl}-70(n=1,630)$ & $249(15.3 \%)$ & $37(15.7 \%)$ & $212(15.2 \%)$ & 0.829 \\
\hline $\operatorname{RNAP}(n=1,101)$ & $155(14.0 \%)$ & $23(13.6 \%)$ & $132(14.1 \%)$ & 0.873 \\
\hline SSc-specific antibody negative $(n=1,556)$ & $460(29.6 \%)$ & $74(32.9 \%)$ & $386(29.0 \%)$ & 0.237 \\
\hline \multicolumn{5}{|l|}{ Clinical manifestations $^{* * * *}$} \\
\hline Telangiectasia $(n=1,704)$ & $1,477(86.7 \%)$ & $214(87.7 \%)$ & $1,263(6.5 \%)$ & 0.610 \\
\hline Calcinosis $(n=1,705)$ & $676(39.7 \%)$ & $94(38.4 \%)$ & $582(39.9 \%)$ & 0.658 \\
\hline Digital ulceration $(\mathrm{n}=1,721)$ & $801(46.5 \%)$ & $105(42.9 \%)$ & $696(47.1 \%)$ & 0.212 \\
\hline GIT involvement $(n=1,727)$ & $1,445(83.7 \%)$ & $210(85.7 \%)$ & $1,235(83.3 \%)$ & 0.350 \\
\hline $\operatorname{ILD}(\mathrm{HRCT} \text { scan })^{\#}(\mathrm{n}=874)^{\#}$ & $489(28.3 \%)$ & $86(35.1 \%)$ & $403(27.2 \%)$ & 0.011 \\
\hline $\mathrm{PAH}^{\# \#}(\mathrm{n}=1,727)$ & $210(12.2 \%)$ & $44(17.9 \%)$ & $166(11.2 \%)$ & 0.003 \\
\hline Body Mass Index, highest recorded $(n=1,673)$ & $27.2(8.2)$ & $27.2(6.3)$ & $27.2(8.4)$ & 0.978 \\
\hline \multicolumn{5}{|l|}{ Medications } \\
\hline Calcium channel blockers (CCB) & $1,121(64.9 \%)$ & $178(72.7 \%)$ & $943(63.6 \%)$ & 0.006 \\
\hline Extended period on $\mathrm{CCB}^{\wedge}$ & $625(36.2 \%)$ & $113(46.1 \%)$ & $512(34.6 \%)$ & $<0.001$ \\
\hline Hormone replacement therapy $(\mathrm{HRT})(\mathrm{n}=1,727)$ & $284(16.4 \%)$ & $45(18.4 \%)$ & $239(16.3 \%)$ & 0.381 \\
\hline Immunosuppression & $949(54.9 \%)$ & $140(57.1 \%)$ & $809(54.6 \%)$ & 0.457 \\
\hline Extended period on immunosuppression ${ }^{\wedge}$ & $429(24.8 \%)$ & $63(25.7 \%)$ & $366(24.7 \%)$ & 0.733 \\
\hline DMARD / corticosteroid & $964(55.8 \%)$ & $142(57.9 \%)$ & $822(55.5 \%)$ & 0.467 \\
\hline
\end{tabular}

This article is protected by copyright. All rights reserved 


\begin{tabular}{|c|c|c|c|c|}
\hline Prednisolone (PNL) & $762(44.1 \%)$ & $114(46.5 \%)$ & $648(43.7 \%)$ & 0.413 \\
\hline Cyclophosphamide & $153(8.9 \%)$ & $32(13.1 \%)$ & $121(8.2 \%)$ & 0.012 \\
\hline Mycophenolate Mofetil (MMF) & $189(10.9 \%)$ & $25(10.2 \%)$ & $164(11.1 \%)$ & 0.689 \\
\hline Methotrexate (MTX) & $378(21.9 \%)$ & $51(20.8 \%)$ & $327(22.1 \%)$ & 0.658 \\
\hline Leflunomide (LEF) & $16(0.9 \%)$ & $2(0.8 \%)$ & $14(0.9 \%)$ & 0.846 \\
\hline Azathioprine (AZA) & $136(7.9 \%)$ & $26(10.6 \%)$ & $110(7.4 \%)$ & 0.086 \\
\hline Hydroxycholorquine (PLQ) & $340(19.7 \%)$ & $39(15.9 \%)$ & $301(20.3 \%)$ & 0109 \\
\hline Cyclosporin & $26(1.5 \%)$ & $3(1.2 \%)$ & $23(1.6 \%)$ & 0.697 \\
\hline $\mathrm{bDMARD}^{\wedge \wedge}$ & $40(2.3 \%)$ & $11(4.9 \%)$ & $29(1.9 \%)$ & 0.004 \\
\hline Rituximab & $20(1.2 \%)$ & $8(3.3 \%)$ & $12(0.8 \%)$ & 0.001 \\
\hline TNF inhibitor & $12(0.7 \%)$ & $3(1.2 \%)$ & $9(0.6 \%)$ & 0.281 \\
\hline Abatacept & $4(0.2 \%)$ & $1(0.4 \%)$ & $3(0.2 \%)$ & 0.535 \\
\hline Tocilizumab & $10(0.6 \%)$ & $0(0 \%)$ & $10(0.7 \%)$ & 0.197 \\
\hline \multicolumn{5}{|l|}{ HRQoL } \\
\hline $\operatorname{PCS}(n=1,284)$ & $38.2(10.5)$ & $35.5(10.2)$ & $38.7(10.5)$ & $<0.001$ \\
\hline $\operatorname{MCS}(n=1,284)$ & $46.0(16.6)$ & $44.3(13.3)$ & $46.2(17.0)$ & 0.158 \\
\hline \multicolumn{5}{|c|}{$\begin{array}{l}\text { Abbreviations: Interstitial lung disease (ILD), pulmonary arterial hypertension (PAH), gastrointestinal tract (GIT), disease modifying anti-rheumatic drugs (DMARDs), biological disease modifying } \\
\text { anti-rheumatic drugs (bDMARDs), hormone replacement therapy (HRT), tumour necrosis factor (TNF), anticentromere (ACA), antitopoisomerase-1 (Scl-70), anti RNA Polymerase (RNAP) III, body } \\
\text { mass index (BMI) health related quality of life (HRQoL) was defined using the SF-36 study short form which provides a score range from 0-100. Scores below } 50 \text { indicate worse HRQoL than the } \\
\text { population normative score and every } 10 \text { points indicates } 1 \text { standard deviation. These scores can be summarized into the physical component score (PCS) and mental component score (MCS), Scores } \\
\text { below } 50 \text { indicate worse HRQoL than the population normative score and every } 10 \text { points indicates } 1 \text { standard deviation. } \\
\text { *SSc onset defined as the first symptom of SSc (Raynaud phenomenon or other) }\end{array}$} \\
\hline
\end{tabular}

This article is protected by copyright. All rights reserved 
*** $\mathrm{n}$ denotes the number of patients who underwent the bloods test thereby determining if they were positive or negative

**** disease manifestation defined as present if present ever from SSc onset

"ILD defined based on characteristic changes on high-resolution computer tomography (HRCT) lung; 874 patients underwent a HRCT based on clinical suspicion of ILD or abnormal respiratory function tests.

\# PAH diagnosed on right heart catheterization (RHC) according to international criteria [11]

\#\#\# all patients with cancer were treated with Rituximab post cancer diagnosis not prior.

\#\#\#\#西 HRQoL over the follow-up period

^ Extended time on therapy (either CCB or immunosuppression) defined as $\geq 2$ consecutive years on therapy or $\geq 50 \%$ of follow-up time if follow-up time was $<2$ years

$\wedge^{\wedge}$ During 2008-2015, 20 SSc patients were treated with Rituximab ( 8 with cancer, 12 without cancer), 12 patients with a tumor necrosis factor (TNF) inhibitor (3 with cancer, 9 without cancer), 10 with tocilizumab (all without cancer) and 4 with abatacept (1 with cancer, 3 without cancer).

Table 2. Cancer details

\begin{tabular}{|l|c|c|}
\hline \multirow{2}{*}{ Organ involved* } & Cancer & \multirow{2}{*}{ Total (\%) } \\
\cline { 2 - 2 } & $\mathbf{n}=\mathbf{2 4 5}$ & \\
\cline { 2 - 3 } & \multicolumn{2}{|c|}{$74(30.2 \%)$} \\
\hline Breast cancer & 74 & $37(18.5 \%)$ \\
\hline Melanoma skin cancer & 37 & \\
\hline Haematological malignancy & 15 & \multirow{2}{*}{$33(13.5 \%)$} \\
Lymphoma & 13 & \\
Non Hodgkin & 2 & $33(13.5 \%)$ \\
Hodgkin & 6 & \\
Leukaemia & 12 & \\
Other Haematologic & & \\
\hline Female genitalia & & \\
\hline
\end{tabular}

This article is protected by copyright. All rights reserved 


\begin{tabular}{|c|c|c|}
\hline $\begin{array}{l}\text { Cervix } \\
\text { Ovary } \\
\text { Uterus }\end{array}$ & $\begin{array}{l}17 \\
8 \\
8\end{array}$ & \\
\hline Lung cancer & 25 & $25(10.2 \%)$ \\
\hline $\begin{array}{l}\text { Gastrointestinal } \\
\text { Colon } \\
\text { Esophagus } \\
\text { Stomach } \\
\text { Pancreas }\end{array}$ & $\begin{array}{c}21 \\
5 \\
2 \\
1\end{array}$ & $29(11.8 \%)$ \\
\hline $\begin{array}{l}\text { Bladder } \\
\text { Prostate } \\
\text { Kidney } \\
\text { Testicular }\end{array}$ & $\begin{array}{c}1 \\
10 \\
5 \\
2\end{array}$ & $18(7.3 \%)$ \\
\hline Brain & 4 & $4(1.6 \%)$ \\
\hline Thyroid gland & 4 & $4(1.6 \%)$ \\
\hline Primary Liver Cancer & 2 & $2(0.8 \%)$ \\
\hline Sarcoma & 1 & $1(0.1 \%)$ \\
\hline Unknown primary site & 13 & $13(5.3 \%)$ \\
\hline Patients with $>1$ cancer & 43 & $43(17.6 \%)$ \\
\hline
\end{tabular}

This article is protected by copyright. All rights reserved 
Table 3. Standardized incidence ratios (SIR) and standardized mortality ratio (SMR)

\begin{tabular}{|c|c|}
\hline Cancer type & SIR $(95 \%$ CI $) *$ \\
\hline Overall cancer & $2.15(1.84-2.49)$ \\
\hline Overall cancer - early^ & $2.53(1.82-3.44)$ \\
\hline Overall cancer - late ${ }^{\wedge}$ & $1.54(1.22-1.91)$ \\
\hline Breast cancer & $1.51(0.98-2.21)$ \\
\hline Breast cancer - early^ $^{\wedge}$ & $3.07(1.47-5.64)$ \\
\hline Breast cancer - late ${ }^{\wedge}$ & $1.38(0.79-2.25)$ \\
\hline Lung cancer & $2.12(1.21-3.44)$ \\
\hline Lung cancer - early^ & $2.05(0.42-6.00)$ \\
\hline Lung cancer - late ${ }^{\wedge}$ & $2.51(1.34-4.29)$ \\
\hline Melanoma skin cancer & $1.30(0.59-2.46)$ \\
\hline Melanoma skin cancer - early^ & $3.40(1.10-7.93)$ \\
\hline Melanoma skin cancer - late ${ }^{\wedge}$ & $0.87(0.24-2.22)$ \\
\hline Colon cancer & $1.26(0.58-2.40)$ \\
\hline Colon cancer - early^ & $2.94(0.80-7.53)$ \\
\hline Colon cancer - late ${ }^{\wedge}$ & $1.03(0.33-2.39)$ \\
\hline Cervical cancer & $4.68(0.97-13.68)$ \\
\hline Cervical cancer - early^ ${ }^{\wedge}$ & $6.89(0.17-38.39)$ \\
\hline
\end{tabular}

This article is protected by copyright. All rights reserved 


\begin{tabular}{|c|c|}
\hline Cervical cancer - late ${ }^{\wedge}$ & $4.94(0.60-17.84)$ \\
\hline Ovarian cancer & $1.86(0.38-5.44)$ \\
\hline Ovarian cancer - early^ $^{\wedge}$ & $6.46(0.78-23.35)$ \\
\hline Ovarian cancer - early^ & $0.92(0.02-5.14)$ \\
\hline Uterine cancer & $1.53(0.50-3.58)$ \\
\hline Uterine cancer - early^ & $1.63(0.04-9.08)$ \\
\hline Uterine cancer - late ${ }^{\wedge}$ & $1.82(0.50-4.66)$ \\
\hline Prostate cancer & $1.34(0.49-2.92)$ \\
\hline Prostate cancer - early^ & $1.56(0.19-5.62)$ \\
\hline Prostate cancer - late ${ }^{\wedge}$ & $1.36(0.37-3.48)$ \\
\hline Haematological cancer & $1.36(0.55-2.81)$ \\
\hline Haematological cancer -early^ & $0.97(0.02-5.42)$ \\
\hline Haematological cancer - late ${ }^{\wedge}$ & $0.97(0.02-5.42)$ \\
\hline Non-Hodgkin's Lymphoma & $1.98(0.73-4.30)$ \\
\hline Non-Hodgkin’s Lymphoma - early^ & $1.66(0.04-9.25)$ \\
\hline Non-Hodgkin's Lymphoma - late^ & $2.43(0.79-5.68)$ \\
\hline Leukaemia & $0.52(0.01-2.91)$ \\
\hline All-cause mortality & $\operatorname{SMR}(95 \% \mathrm{CI})^{*}$ \\
\hline All-cause mortality in the whole SSc cohort & $2.37(2.08-2.70)$ \\
\hline
\end{tabular}

This article is protected by copyright. All rights reserved 


\begin{tabular}{|l|l|}
\hline All-cause mortality for non-cancer patients & $2.19(1.87-2.54)$ \\
\hline All-cause mortality for cancer patients & $3.13(2.39-4.02)$ \\
\hline
\end{tabular}

Abbreviations: Standardized incidence ratios (SIR), Standardized mortality ratios (SMR), confidence intervals (CI)

Cancers included in the SIR calculation include all incident cancers diagnosed btw 2008-2015

* SIR was calculated using the exact Poisson method

SMR was calculated for the whole cohort and by cancer status. SMR based on all cause mortality, not cancer specific mortality

$\wedge^{\wedge}$ Early cancer defined as cancer incidence within 5 years of onset of SSc (Raynaud phenomenon or other)

${ }^{\wedge}$ Late cancer defined as cancer incidence after 5 years since onset of SSc (Raynaud phenomenon or other)Table 4. Determinants of cancer risk by multivariable logistic regression analysis

\begin{tabular}{|l|c|c|}
\hline Correlates of cancer & OR (95\% CI) & p-value \\
\hline Age at SSc onset*, years & $1.02(1.01-1.03)$ & 0.001 \\
\hline Female & $1.18(0.77-1.80)$ & 0.449 \\
\hline White ethnicity & $1.89(0.96-3.72)$ & 0.064 \\
\hline History of smoking (current or previous) & $1.12(0.85-1.53)$ & 0.456 \\
\hline Extended immunosuppression ${ }^{\wedge}$ & $0.88(0.63-1.22)$ & 0.430 \\
\hline Interstitial lung disease $^{*} 1.46(1.07-2.00)$ & 0.017 \\
\hline Pulmonary arterial hypertension & $1.53(1.04-2.25)$ & 0.021 \\
\hline Extended calcium channel blockers therapy^ & $1.47(1.06-2.02)$ & 0.016 \\
\hline \multicolumn{2}{|l}{} & OR (95\% CI) \\
\hline Correlates of early versus late cancer** & \multicolumn{1}{|l}{} \\
\hline
\end{tabular}

This article is protected by copyright. All rights reserved 


\begin{tabular}{|l|l|c|}
\hline Age at SSc onset*, years & $1.05(1.02-1.08)$ & 0.004 \\
\hline Female & $1.31(0.37-4.69)$ & 0.675 \\
\hline Caucasian ethnicity & $0.53(0.10-2.53)$ & 0.425 \\
\hline History of smoking (current or previous) & $0.94(0.46-1.95)$ & 0.872 \\
\hline Extended period on immunosuppression & $0.60(0.25-1.46)$ & 0.264 \\
\hline Digital ulceration & $0.43(0.19-0.97)$ & 0.042 \\
\hline RNAP antibody & $2.91(1.05-8.21)$ & 0.044 \\
\hline Extended period on calcium channel blockers therapy & $1.09(0.50-2.36)$ & 0.830 \\
\hline & & \\
\hline Correlates of early cancer versus no cancer*** & OR (95\% CI) & \\
\hline Age at SSc onset*, years & $1.05(1.03-1.08)$ & $<0.001$ \\
\hline Female & $1.51(0.56-4.13)$ & 0.418 \\
\hline Caucasian ethnicity & $1.25(0.36-4.31)$ & 0.726 \\
\hline History of smoking (current or previous) & $1.05(0.57-1.93)$ & 0.880 \\
\hline Extended period on immunosuppression^^ & $0.62(0.31-1.24)$ & 0.180 \\
\hline Digital ulceration & $0.44(0.22-0.87)$ & 0.018 \\
\hline RNAP antibody & $2.14(1.03-4.45)$ & 0.043 \\
\hline
\end{tabular}

Abbreviations: systemic sclerosis (SSc), anticentromere (ACA), anti RNA Polymerase (RNAP) III

*SSc onset defined as the first symptom of SSc (Raynaud phenomenon or other)

**early cancer defined as diagnosed within five years of the onset of the first clinical manifestation of SSc (Raynaud phenomenon or other)

*** early cancer defined as diagnosed within five years of the onset of SSc skin changes compared with SSc patients without cancer with at least five years of disease duration since SSc onset (Raynaud phenomenon or other)

This article is protected by copyright. All rights reserved 
${ }^{\wedge}$ Extended period on therapy (either CCB or immunosuppression) defined as $\geq 2$ consecutive years on therapy or $\geq 50 \%$ of follow-up time in ASCS if follow-up time was $<2$ years

Table 5. Correlates of cancer types by multivariable logistic regression analysis

\begin{tabular}{|l|c|c|}
\hline Correlates of breast cancer (n=74) & OR (95\% CI) & P \\
\hline Age at SSc onset*, years & $1.03(1.01-1.05)$ & 0.005 \\
\hline Caucasian ethnicity & $1.57(0.48-5.12)$ & 0.457 \\
\hline History of smoking (current or previous) & $1.13(0.69-1.83)$ & 0.626 \\
\hline Extended period on immunosuppression^ & $0.79(0.45-1.41)$ & 0.430 \\
\hline $\begin{array}{l}\text { Extended period on calcium channel blockers } \\
\text { therapy^ }\end{array}$ & $1.61(0.99-2.63)$ & 0.051 \\
\hline Pregnancy history & $0.66(0.45-0.98)$ & 0.041 \\
\hline GIT manifestations & $2.99(1.07-8.36)$ & 0.036 \\
\hline \multicolumn{1}{|l|}{} & $1.07(1.03-1.11)$ & $<0.001$ \\
\hline Correlates of early breast cancer (n=27) & $1.69(0.22-13.3)$ & 0.617 \\
\hline Age at SSc onset*, years & $0.42(0.15-1.12)$ & 0.095 \\
\hline Caucasian ethnicity & $1.12(0.33-3.72)$ & 0.859 \\
\hline History of smoking (current or previous) & $0.81(0.29-2.27)$ & 0.691 \\
\hline Limited disease subtype & & \\
\hline Extended period on immunosuppressive therapy^ & & \\
\hline
\end{tabular}

This article is protected by copyright. All rights reserved 


\begin{tabular}{|c|c|c|}
\hline Pregnancy history & $0.87(0.39-1.92)$ & 0.727 \\
\hline Renal crisis & $2.36(0.45-12.3)$ & 0.309 \\
\hline RNAP antibody & $4.28(1.29-14.2)$ & 0.018 \\
\hline \multicolumn{3}{|l|}{ 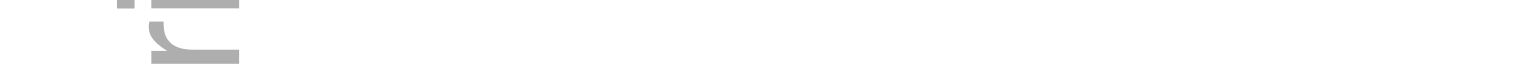 } \\
\hline Correlates of lung cancer $(n=25)$ & OR $(95 \% \mathrm{CI})$ & $\mathbf{P}$ \\
\hline Age at SSc onset*, years & $1.01(0.97-1.03)$ & 0.810 \\
\hline Female & $2.08(0.57-7.51)$ & 0.266 \\
\hline White ethnicity & $1.04(0.23-4.69)$ & 0.960 \\
\hline History of smoking (current or previous) & $1.79(0.73-4.39)$ & 0.203 \\
\hline Extended period on mmunosuppressive therapy $^{\wedge}$ & $1.03(0.42-2.56)$ & 0.943 \\
\hline Anticentromere antibody (ACA) positive & $0.22(0.06-0.81)$ & 0.023 \\
\hline Interstitial lung disease (ILD) & $2.83(1.09-7.31)$ & 0.031 \\
\hline Pulmonary arterial hypertension (PAH) & $2.52(0.94-6.81)$ & 0.068 \\
\hline Correlates of hematological cancer $(n=32)$ & OR $(95 \% \mathrm{CI})$ & $\mathbf{P}$ \\
\hline Age at SSc onset*, years & $1.04(1.01-1.07)$ & 0.007 \\
\hline Female & $0.79(0.31-2.03)$ & 0.622 \\
\hline History of smoking (current or previous) & $1.14(0.52-2.43)$ & 0.736 \\
\hline Extended period on immunosuppressive therapy ${ }^{\wedge}$ & $1.27(0.58-2.79)$ & 0.557 \\
\hline SSc-specific antibody negative & $0.35(0.16-0.73)$ & 0.005 \\
\hline
\end{tabular}

This article is protected by copyright. All rights reserved 


\begin{tabular}{|l|c|c|}
\hline & & \\
\hline Correlates of melanoma (n=37) & OR (95\% CI) & P \\
\hline Age at SSc onset*, years & $1.01(0.99-1.03)$ & 0.428 \\
\hline Female & $0.69(0.28-1.73)$ & 0.432 \\
\hline History of smoking (current or previous) & $0.52(0.26-1.05)$ & 0.066 \\
\hline $\begin{array}{l}\text { Extended period on calcium channel blockers } \\
\text { therapy^ }\end{array}$ & $2.01(1.03-3.95)$ & 0.042 \\
\hline Extended period on immunosuppressive therapy^ & $0.62(0.27-1.43)$ & 0.262 \\
\hline \multicolumn{1}{|c|}{} & & \\
\hline Correlates of early melanoma (n=11) $^{\wedge}$ & $1.07(1.02-1.13)$ & 0.005 \\
\hline Age at SSc onset*, years & $0.34(0.08-1.38)$ & 0.131 \\
\hline Female & $0.48(0.13-1.75)$ & 0.266 \\
\hline History of smoking (current or previous) & $0.89(0.27-3.00)$ & 0.858 \\
\hline Immunosuppressive therapy & & \\
\hline
\end{tabular}

*SSc onset defined as the first symptom of SSc (Raynaud phenomenon or other)

${ }^{\wedge}$ Extended period on therapy defined as $\geq 2$ consecutive years on therapy or $\geq 50 \%$ of follow-up time in ASCS if follow-up time was $<2$ years .

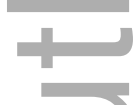

Table 6. Healthcare utilization and associated cost by cancer status (2008-2015)

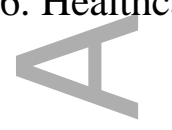

This article is protected by copyright. All rights reserved 


\begin{tabular}{|c|c|c|c|}
\hline Episodes of care / total healthcare cost (AUD\$) & $\begin{array}{c}\text { Cancer } \\
\text { Median }\left(25^{\text {th }}-\mathbf{- 7 5}^{\text {th }}\right)\end{array}$ & $\begin{array}{c}\text { No Cancer } \\
\text { Median }\left(25^{\text {th }}-75^{\text {th }}\right)\end{array}$ & $\begin{array}{c}\mathrm{p}- \\
\text { value }\end{array}$ \\
\hline $\begin{array}{l}\text { Total healthcare cost per patient } 2008-2015 \\
\text { Average annual cost per patient consisting of: } \\
\text { average annual admission cost per patient } \\
\text { average annual ED presentation cost per patient } \\
\text { average annual MBS service cost per patient }\end{array}$ & $\begin{array}{c}52,798(32,172-103,516) \\
8,816(6,401-12,308) \\
4,196.6(2,676-6,489) \\
443(0-866) \\
3,164(2,173-5,825)\end{array}$ & $\begin{array}{c}35,810(16,467-35,810) \\
7,320(5,076-10,368) \\
3,776(2,291-5,928) \\
422(0-746) \\
2,319(1,380-3,502)\end{array}$ & $\begin{array}{c}<0.001 \\
<0.001 \\
0.050 \\
0.314 \\
<0.001\end{array}$ \\
\hline $\begin{array}{l}\text { Hospitalizations } \\
\text { Frequency of hospital visits per patient per annum } \\
\text { LOS per episode } \\
\text { Reason for hospital admission (top three) } \\
\end{array}$ & $\begin{array}{c}2.4(1-4.4) \\
1(1-2) \\
\text { Hemodialysis } \\
\text { Antineoplastic agent administration } \\
\text { SSc }\end{array}$ & $\begin{array}{c}1.7(1-3) \\
1(1-3) \\
\text { SSc } \\
\text { Iron deficiency anaemia } \\
\text { Cataract }\end{array}$ & $\begin{array}{l}0.001 \\
0.415\end{array}$ \\
\hline $\begin{array}{l}\text { ED presentations } \\
\text { Annual frequency of presentations per patient } \\
\text { Reason for ED presentation (top three) }\end{array}$ & $\begin{array}{l}\text { 1(1-2) } \\
\text { Chest pain } \\
\text { Intestinal obstruction } \\
\text { Acute LRTI }\end{array}$ & $\begin{array}{l}1(1-1.7) \\
\text { Chest pain } \\
\text { Intestinal obstruction } \\
\text { Dyspnoea }\end{array}$ & 0.247 \\
\hline
\end{tabular}

This article is protected by copyright. All rights reserved 


\begin{tabular}{|c|c|c|c|}
\hline \multicolumn{4}{|l|}{ MBS utilization } \\
\hline $\begin{array}{l}\text { Annual frequency of service utilization per patient } \\
\text { Services utilized (top three) }\end{array}$ & $88(57-144)$ & $73(45-121)$ & $<0.001$ \\
\hline 2 & Professional attendances $(29.8 \%)$ & Professional attendances $(30.2 \%)$ & \\
\hline 3 & Allied health services $(14.0 \%)$ & Allied health services $(14.2 \%)$ & \\
\hline
\end{tabular}

(SD), interquartile range (IQR). Medical Benefits Schedule (MBS), Emergency department (ED), length of stay (LOS), lower respiratory tract infection (LRTI), scleroderma (SSc), All costs are in Australian Dollars (AUD)

Figure 1(a) Survival in SSc patients with and without cancer in the ASCS prevalent cohort

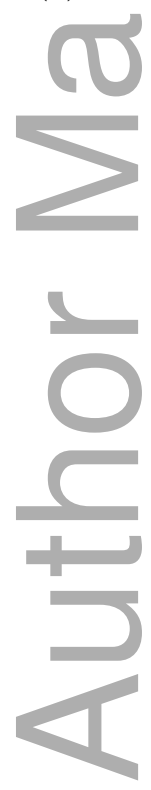

This article is protected by copyright. All rights reserved 


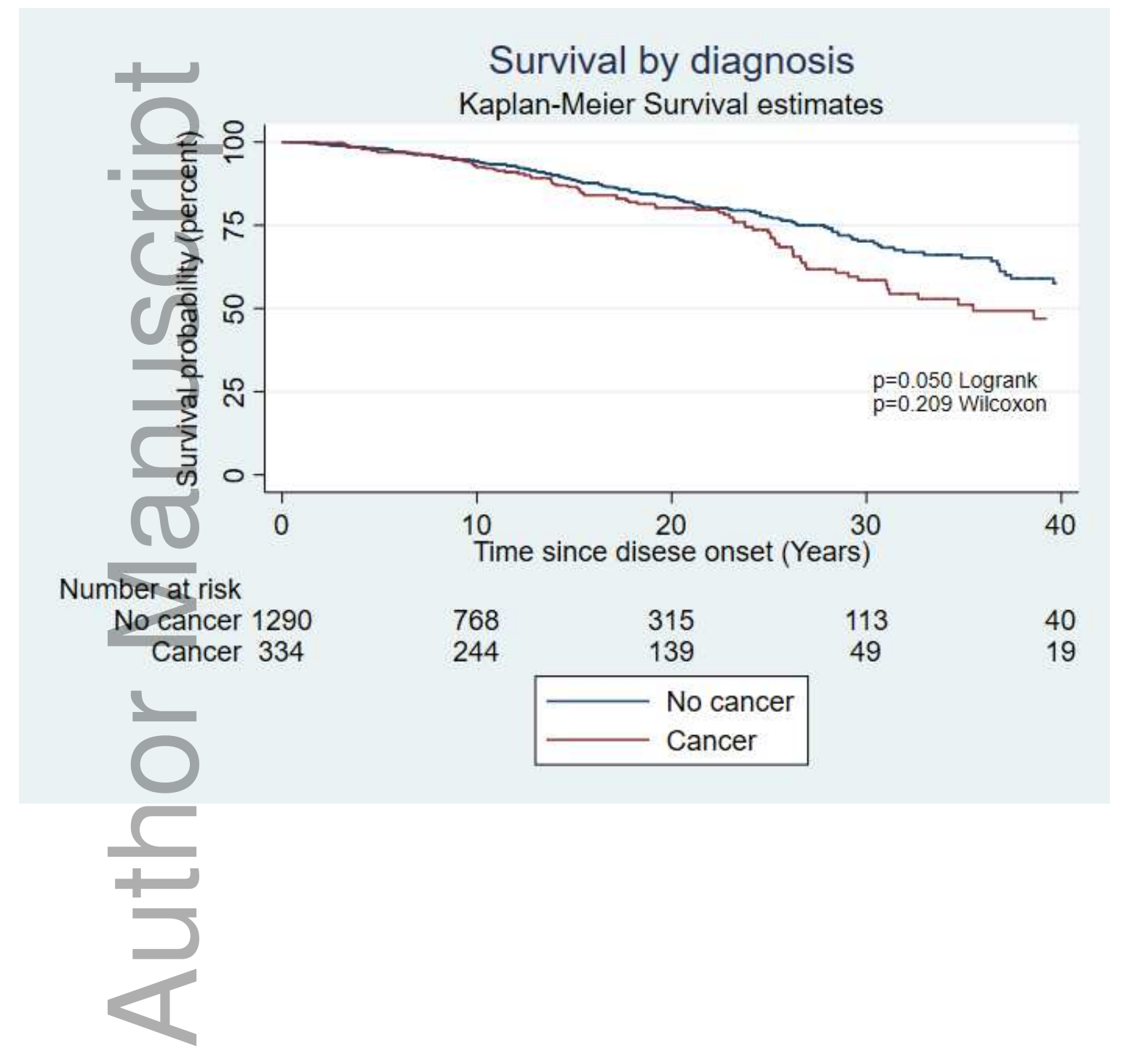

This article is protected by copyright. All rights reserved 
Figure 1(b) Survival of SSc patients with and without cancer in an incident cohort (defined as SSc patients enrolled in the ASCS within two years of SSc disease onset*)

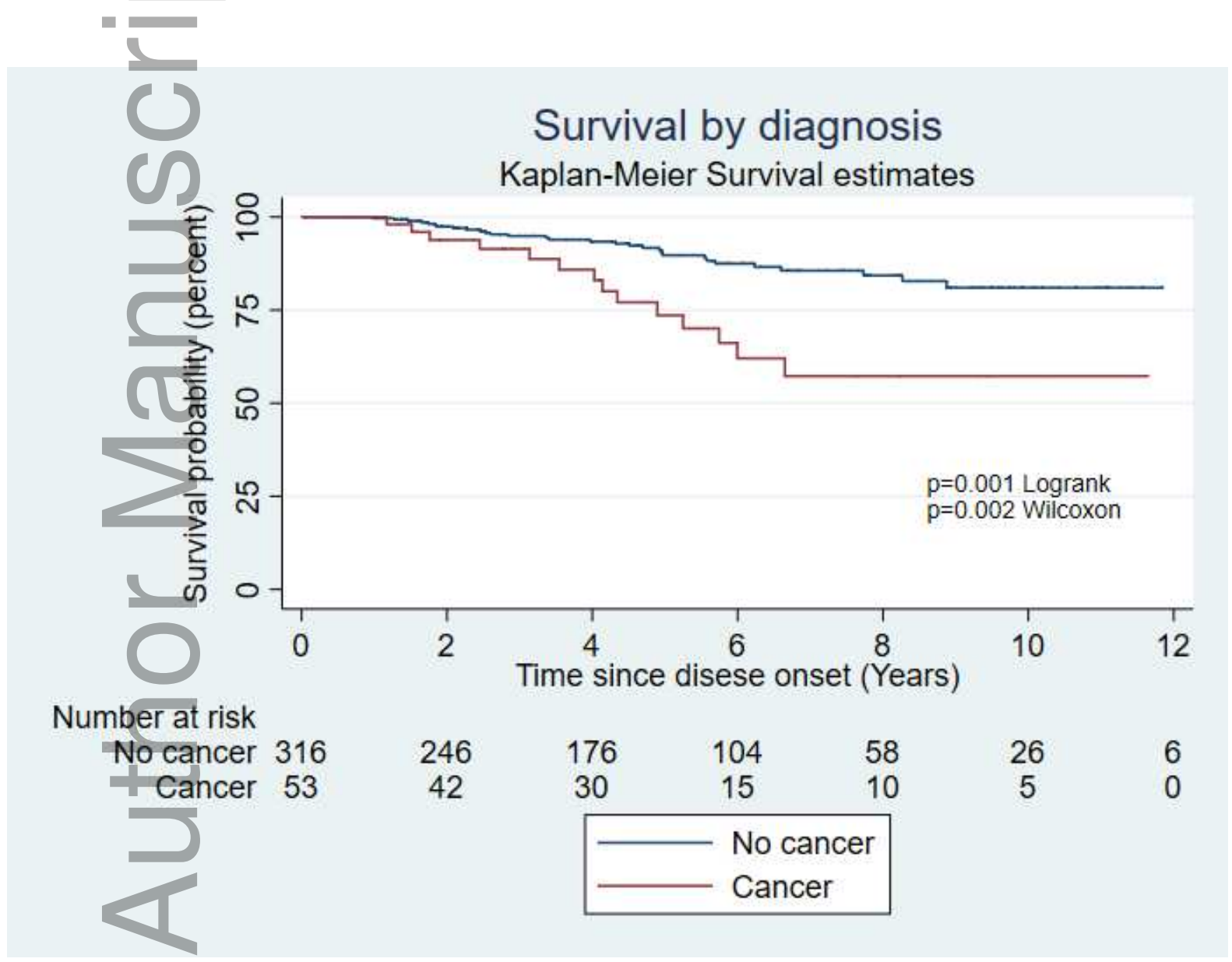

This article is protected by copyright. All rights reserved 
*SSc onset defined as the first symptom of SSc (Raynaud phenomenon or other)

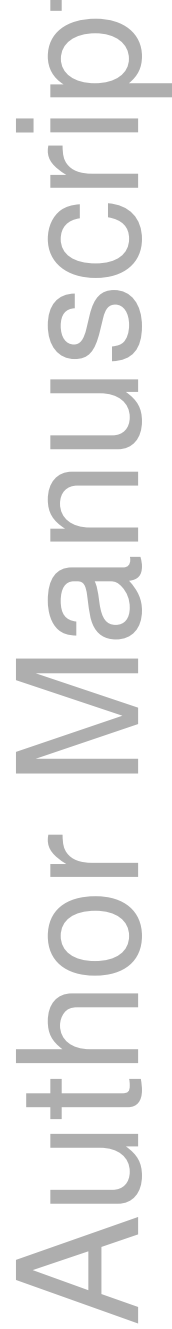

This article is protected by copyright. All rights reserved 
Table 1. Patient characteristics $(n=1,727)$

\begin{tabular}{|c|c|c|c|c|}
\hline \multirow{3}{*}{ Patient characteristics } & \multirow{2}{*}{$\begin{array}{c}\text { SSc patients } \\
\mathrm{n}=\mathbf{1 , 7 2 7} \\
\end{array}$} & \multirow{2}{*}{$\begin{array}{c}\begin{array}{c}\text { SSc patients } \\
\text { with cancer }\end{array} \\
\mathbf{n}=\mathbf{2 4 5}(\mathbf{1 4 . 2 \%})\end{array}$} & \multirow{2}{*}{$\begin{array}{c}\begin{array}{c}\text { SSc patients } \\
\text { without cancer }\end{array} \\
\mathrm{n}=\mathbf{1 , 4 8 2}(\mathbf{8 5 . 8 \%})\end{array}$} & \multirow{3}{*}{$p$ value } \\
\hline & & & & \\
\hline & $\begin{array}{c}\text { mean } \pm \text { SD } \\
\text { or } \%\end{array}$ & $\begin{array}{c}\text { mean } \pm \text { SD or } \\
\%\end{array}$ & mean \pm SD or $\%$ & \\
\hline \multicolumn{5}{|l|}{ Demographics } \\
\hline Female & $1,483(85.9 \%)$ & $210(85.7 \%)$ & $1,273(85.8 \%)$ & 0.939 \\
\hline Caucasian ethnicity & $1,509(92.1 \%)$ & $226(95.8 \%)$ & $1,283(91.5 \%)$ & 0.023 \\
\hline Age at SSc onset*, years & $46.6(14.3)$ & $49.9(14.3)$ & $46.0(14.3)$ & 0.001 \\
\hline Age at onset of SSc skin involvement, years & $48.5(14.2)$ & $52.5(14.4)$ & $47.8(14.2)$ & 0.001 \\
\hline SSc disease duration $* *$ at recruitment, years & $10.9(10.6)$ & $13.7(12.6)$ & $10.5(10.2)$ & $<0.001$ \\
\hline Follow-up since recruitment, years & $4.1(3.4)$ & $4.3(3.4)$ & $4.1(3.4)$ & 0.452 \\
\hline Limited SSc & $1,266(73.9 \%)$ & $184(75.7 \%)$ & $1,082(73.6 \%)$ & 0.477 \\
\hline Smoking history (current or ever) & $856(50.1 \%)$ & $126(52.7 \%)$ & $730(49.8 \%)$ & 0.513 \\
\hline Pregnancy history & $941(63.5 \%)$ & $139(66.2 \%)$ & $802(63.0 \%)$ & 0.374 \\
\hline Age at cancer diagnosis & - & $57.7(12.9)$ & $47.8(14.2)$ & 0.001 \\
\hline Disease duration at cancer diagnosis & - & $8.1(14.7)$ & - & - \\
\hline Alive at end of follow-up & $1,460(84.5 \%)$ & $178(72.7 \%)$ & $1,282(86.5 \%)$ & $<0.001$ \\
\hline \multicolumn{5}{|l|}{ Scleroderma-specific antibodies ${ }^{* * *}$} \\
\hline $\mathrm{ACA}(\mathrm{n}=1,656)$ & $796(48.1 \%)$ & $107(44.9 \%)$ & $689(48.6 \%)$ & 0.299 \\
\hline $\operatorname{Scl}-70(n=1,630)$ & $249(15.3 \%)$ & $37(15.7 \%)$ & $212(15.2 \%)$ & 0.829 \\
\hline $\operatorname{RNAP}(\mathrm{n}=1,101)$ & $155(14.0 \%)$ & $23(13.6 \%)$ & $132(14.1 \%)$ & 0.873 \\
\hline SSc-specific antibody negative $(n=1,556)$ & $460(29.6 \%)$ & $74(32.9 \%)$ & $386(29.0 \%)$ & 0.237 \\
\hline \multicolumn{5}{|l|}{ Clinical manifestations ${ }^{* * * *}$} \\
\hline Telangiectasia $(\mathrm{n}=1,704)$ & $1,477(86.7 \%)$ & $214(87.7 \%)$ & $1,263(6.5 \%)$ & 0.610 \\
\hline Calcinosis $(\mathrm{n}=1,705)$ & $676(39.7 \%)$ & $94(38.4 \%)$ & $582(39.9 \%)$ & 0.658 \\
\hline Digital ulceration $(n=1,721)$ & $801(46.5 \%)$ & $105(42.9 \%)$ & $696(47.1 \%)$ & 0.212 \\
\hline GIT involvement $(\mathrm{n}=1,727)$ & $1,445(83.7 \%)$ & $210(85.7 \%)$ & $1,235(83.3 \%)$ & 0.350 \\
\hline
\end{tabular}




\begin{tabular}{|c|c|c|c|c|}
\hline $\begin{array}{l}\text { ILD (HRCT scan) }{ }^{\#}(\mathrm{n}=874)^{\#} \\
\text { PAH }^{\# \#}(\mathrm{n}=1,727) \\
\text { Body Mass Index, highest recorded }(\mathrm{n}=1,673)\end{array}$ & $\begin{array}{c}489(28.3 \%) \\
210(12.2 \%) \\
27.2(8.2) \\
\end{array}$ & $\begin{array}{c}86(35.1 \%) \\
44(17.9 \%) \\
27.2(6.3)\end{array}$ & $\begin{array}{c}403(27.2 \%) \\
166(11.2 \%) \\
27.2(8.4)\end{array}$ & $\begin{array}{l}0.011 \\
0.003 \\
0.978 \\
\end{array}$ \\
\hline \multicolumn{5}{|l|}{ Medications } \\
\hline Calcium channel blockers (CCB) & $1,121(64.9 \%)$ & $178(72.7 \%)$ & $943(63.6 \%)$ & 0.006 \\
\hline Extended period on $\mathrm{CCB}^{\wedge}$ & $625(36.2 \%)$ & $113(46.1 \%)$ & $512(34.6 \%)$ & $<0.001$ \\
\hline Hormone replacement therapy $(\mathrm{HRT})(\mathrm{n}=1,727)$ & $284(16.4 \%)$ & $45(18.4 \%)$ & $239(16.3 \%)$ & 0.381 \\
\hline Immunosuppression & $949(54.9 \%)$ & $140(57.1 \%)$ & $809(54.6 \%)$ & 0.457 \\
\hline Extended period on immunosuppression ${ }^{\wedge}$ & $429(24.8 \%)$ & $63(25.7 \%)$ & $366(24.7 \%)$ & 0.733 \\
\hline DMARD / corticosteroid & $964(55.8 \%)$ & $142(57.9 \%)$ & $822(55.5 \%)$ & 0.467 \\
\hline Prednisolone (PNL) & $762(44.1 \%)$ & $114(46.5 \%)$ & $648(43.7 \%)$ & 0.413 \\
\hline Cyclophosphamide & $153(8.9 \%)$ & $32(13.1 \%)$ & $121(8.2 \%)$ & 0.012 \\
\hline Mycophenolate Mofetil (MMF) & $189(10.9 \%)$ & $25(10.2 \%)$ & $164(11.1 \%)$ & 0.689 \\
\hline Methotrexate (MTX) & $378(21.9 \%)$ & $51(20.8 \%)$ & $327(22.1 \%)$ & 0.658 \\
\hline Leflunomide (LEF) & $16(0.9 \%)$ & $2(0.8 \%)$ & $14(0.9 \%)$ & 0.846 \\
\hline Azathioprine (AZA) & $136(7.9 \%)$ & $26(10.6 \%)$ & $110(7.4 \%)$ & 0.086 \\
\hline Hydroxycholorquine (PLQ) & $340(19.7 \%)$ & $39(15.9 \%)$ & $301(20.3 \%)$ & 0109 \\
\hline Cyclosporin & $26(1.5 \%)$ & $3(1.2 \%)$ & $23(1.6 \%)$ & 0.697 \\
\hline $\mathrm{bDMARD}^{\wedge \wedge}$ & $40(2.3 \%)$ & $11(4.9 \%)$ & $29(1.9 \%)$ & 0.004 \\
\hline Rituximab $^{\# \# \#}$ & $20(1.2 \%)$ & $8(3.3 \%)$ & $12(0.8 \%)$ & 0.001 \\
\hline TNF inhibitor & $12(0.7 \%)$ & $3(1.2 \%)$ & $9(0.6 \%)$ & 0.281 \\
\hline Abatacept & $4(0.2 \%)$ & $1(0.4 \%)$ & $3(0.2 \%)$ & 0.535 \\
\hline Tocilizumab & $10(0.6 \%)$ & $0(0 \%)$ & $10(0.7 \%)$ & 0.197 \\
\hline \multicolumn{5}{|l|}{ HRQoL } \\
\hline $\operatorname{PCS}(n=1,284)$ & $38.2(10.5)$ & $35.5(10.2)$ & $38.7(10.5)$ & $<0.001$ \\
\hline $\operatorname{MCS}(n=1,284)$ & $46.0(16.6)$ & $44.3(13.3)$ & $46.2(17.0)$ & 0.158 \\
\hline
\end{tabular}

Abbreviations: Interstitial lung disease (ILD), pulmonary arterial hypertension (PAH), gastrointestinal tract (GIT), disease modifying anti-rheumatic drugs (DMARDs), biological disease modifying anti-rheumatic drugs (bDMARDs), hormone replacement therapy (HRT), tumour necrosis factor (TNF), anticentromere (ACA), antitopoisomerase-1 (Scl-70), anti RNA Polymerase (RNAP) III, body mass index (BMI) health related quality of life (HRQoL) was defined using the SF-36 study short form which provides a score range from 0-100. Scores below 50 indicate worse HRQL than the population normative score and every 10 points indicates 1 standard deviation. These scores can be summarized into the physical component score (PCS) and mental component score (MCS), Scores below 50 indicate worse HRQoL than the population normative score and every 10 points indicates 1 standard deviation.

*SSc onset defined as the first symptom of SSc (Raynaud phenomenon or other)

** disease duration from recruitment 
*** $\mathrm{n}$ denotes the number of patients who underwent the bloods test thereby determining if they were positive or negative

**** disease manifestation defined as present if present ever from SSc onset

\#ILD defined based on characteristic changes on high-resolution computer tomography (HRCT) lung; 874 patients underwent a HRCT based on clinical suspicion of ILD or abnormal respiratory function tests.

\# PAH diagnosed on right heart catheterization (RHC) according to international criteria [11]

\#\#\# all patients with cancer were treated with Rituximab post cancer diagnosis not prior.

\#\#\#\# mean HRQoL over the follow-up period

$\wedge$ Extended time on therapy (either CCB or immunosuppression) defined as $>2$ consecutive years on therapy or $>50 \%$ of follow-up time if follow-up time was $<2$ years

$\wedge \wedge$ During 2008-2015, 20 SSc patients were treated with Rituximab ( 8 with cancer, 12 without cancer), 12 patients with a tumor necrosis factor (TNF) inhibitor ( 3 with cancer, 9 without cancer), 10 with tocilizumab (all without cancer) and 4 with abatacept (1 with cancer, 3 without cancer).

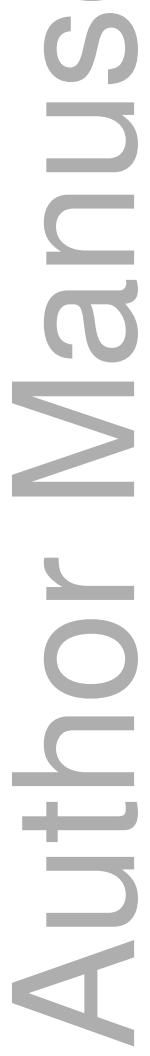


Table 2. Cancer details

\begin{tabular}{|c|c|c|}
\hline \multirow{3}{*}{ Organ involved* } & Cancer & \multirow{3}{*}{ Total $(\%)$} \\
\hline & $n=245$ & \\
\hline & & \\
\hline Breast cancer & 74 & $74(30.2 \%)$ \\
\hline Melanoma skin cancer & 37 & $37(18.5 \%)$ \\
\hline \multicolumn{2}{|l|}{ Haematological malignancy } & \multirow{6}{*}{$33(13.5 \%)$} \\
\hline Lymphoma & 15 & \\
\hline Non Hodgkin & 13 & \\
\hline Hodgkin & 2 & \\
\hline Leukaemia & 6 & \\
\hline Other Haematologic & 12 & \\
\hline \multicolumn{2}{|l|}{ Female genitalia } & \multirow{4}{*}{$33(13.5 \%)$} \\
\hline Cervix & 17 & \\
\hline Ovary & 8 & \\
\hline Uterus & 8 & \\
\hline Lung cancer & 25 & $25(10.2 \%)$ \\
\hline \multicolumn{2}{|l|}{ Gastrointestinal } & \multirow{5}{*}{$29(11.8 \%)$} \\
\hline Colon & 21 & \\
\hline Esophagus & 5 & \\
\hline Stomach & 2 & \\
\hline Pancreas & 1 & \\
\hline Bladder & 1 & \multirow{4}{*}{$18(7.3 \%)$} \\
\hline Prostate & 10 & \\
\hline Kidney & 5 & \\
\hline Testicular & 2 & \\
\hline Brain & 4 & $4(1.6 \%)$ \\
\hline Thyroid gland & 4 & $4(1.6 \%)$ \\
\hline
\end{tabular}




\begin{tabular}{|l|c|c|}
\hline Primary Liver Cancer & 2 & $2(0.8 \%)$ \\
\hline Sarcoma & 1 & $1(0.1 \%)$ \\
\hline Unknown primary site & 13 & $13(5.3 \%)$ \\
\hline Patients with > 1 cancer & 43 & $43(17.6 \%)$ \\
\hline
\end{tabular}

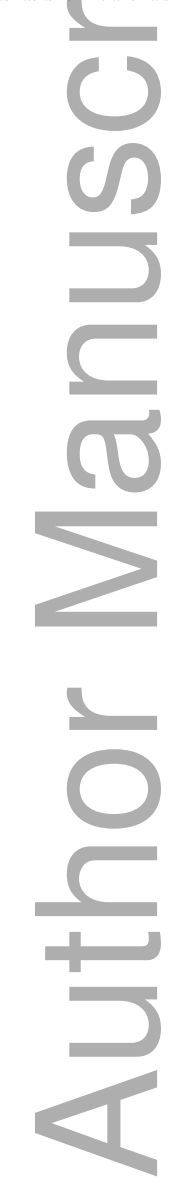

This article is protected by copyright. All rights reserved 
Table 3. Standardized incidence ratios (SIR) and standardized mortality ratio (SMR)

\begin{tabular}{|c|c|}
\hline Cancer type & SIR $(95 \%$ CI $) *$ \\
\hline Overall cancer & $2.15(1.84-2.49)$ \\
\hline Overall cancer - early^ & $2.53(1.82-3.44)$ \\
\hline Overall cancer - late ${ }^{\wedge}$ & $1.54(1.22-1.91)$ \\
\hline Breast cancer & $1.51(0.98-2.21)$ \\
\hline Breast cancer - early^ & $3.07(1.47-5.64)$ \\
\hline Breast cancer - late ${ }^{\wedge}$ & $1.38(0.79-2.25)$ \\
\hline Lung cancer & $2.12(1.21-3.44)$ \\
\hline Lung cancer - early^ & $2.05(0.42-6.00)$ \\
\hline Lung cancer - late ${ }^{\wedge}$ & $2.51(1.34-4.29)$ \\
\hline Melanoma skin cancer & $1.30(0.59-2.46)$ \\
\hline Melanoma skin cancer - early^ & $3.40(1.10-7.93)$ \\
\hline Melanoma skin cancer - late ${ }^{\wedge}$ & $0.87(0.24-2.22)$ \\
\hline Colon cancer & $1.26(0.58-2.40)$ \\
\hline Colon cancer - early^ & $2.94(0.80-7.53)$ \\
\hline Colon cancer - late^ & $1.03(0.33-2.39)$ \\
\hline Cervical cancer & $4.68(0.97-13.68)$ \\
\hline Cervical cancer - early^ & $6.89(0.17-38.39)$ \\
\hline Cervical cancer - late ${ }^{\wedge}$ & $4.94(0.60-17.84)$ \\
\hline Ovarian cancer & $1.86(0.38-5.44)$ \\
\hline Ovarian cancer - early^ ${ }^{\wedge}$ & $6.46(0.78-23.35)$ \\
\hline Ovarian cancer - early^ & $0.92(0.02-5.14)$ \\
\hline Uterine cancer & $1.53(0.50-3.58)$ \\
\hline Uterine cancer - early^ ${ }^{\wedge}$ & $1.63(0.04-9.08)$ \\
\hline
\end{tabular}




\begin{tabular}{|c|c|}
\hline Uterine cancer - late & $1.82(0.50-4.66)$ \\
\hline Prostate cancer & $1.34(0.49-2.92)$ \\
\hline Prostate cancer - early^ $^{\wedge}$ & $1.56(0.19-5.62)$ \\
\hline Prostate cancer - late & $1.36(0.37-3.48)$ \\
\hline Haematölogical cancer & $1.36(0.55-2.81)$ \\
\hline Haematological cancer -early^ & $0.97(0.02-5.42)$ \\
\hline Haematological cancer - late & $0.97(0.02-5.42)$ \\
\hline Non-Hodgkin's Lymphoma & $1.98(0.73-4.30)$ \\
\hline Non-Hodgkin's Lymphoma - early^ & $1.66(0.04-9.25)$ \\
\hline Non-Hodgkin's Lymphoma - late & $2.43(0.79-5.68)$ \\
\hline Leukaemia & $0.52(0.01-2.91)$ \\
\hline \multicolumn{2}{|c|}{} \\
\hline All-cause mortality & SMR (95\% CI)* \\
\hline All-cause mortality in the whole SSc cohort & $2.37(2.08-2.70)$ \\
\hline All-cause mortality for non-cancer patients & $2.19(1.87-2.54)$ \\
\hline All-cause mortality for cancer patients & $3.13(2.39-4.02)$ \\
\hline
\end{tabular}

Abbreviations: Standardized incidence ratios (SIR), Standardized mortality ratios (SMR), confidence intervals (CI) Cancers included in the SIR calculation include all incident cancers diagnosed btw 2008-2015

* SIR was calculated using the exact Poisson method

SMR was calculated for the whole cohort and by cancer status. SMR based on all cause mortality, not cancer specific mortality

$\wedge^{\wedge}$ Early cancer defined as cancer incidence within 5 years of onset of SSc (Raynaud phenomenon or other)

${ }^{\wedge}$ Late cancer defined as cancer incidence after 5 years since onset of SSc (Raynaud phenomenon or other)

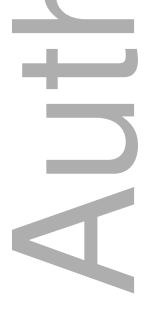


Table 4. Determinants of cancer risk by multivariable logistic regression analysis

\begin{tabular}{|l|c|c|}
\hline Correlates of cancer & OR (95\% CI) & p-value \\
\hline Age at SSc onset*, years & $1.02(1.01-1.03)$ & 0.001 \\
\hline Female & $1.18(0.77-1.80)$ & 0.449 \\
\hline White ethnicity & $1.89(0.96-3.72)$ & 0.064 \\
\hline History of smoking (current or previous) & $1.12(0.85-1.53)$ & 0.456 \\
\hline Extended immunosuppression ${ }^{\wedge}$ & $0.88(0.63-1.22)$ & 0.430 \\
\hline Interstitial lung disease & $1.46(1.07-2.00)$ & 0.017 \\
\hline Pulmonary arterial hypertension & $1.53(1.04-2.25)$ & 0.021 \\
\hline Extended calcium channel blockers therapy^ & $1.47(1.06-2.02)$ & 0.016 \\
\hline \multicolumn{2}{|c|}{} & \\
\hline Correlates of early versus late cancer** & OR (95\% CI) & \\
\hline Age at SSc onset*, years & $1.05(1.02-1.08)$ & 0.004 \\
\hline Female & $1.31(0.37-4.69)$ & 0.675 \\
\hline Caucasian ethnicity & $0.53(0.10-2.53)$ & 0.425 \\
\hline History of smoking (current or previous) & $0.94(0.46-1.95)$ & 0.872 \\
\hline Extended period on immunosuppression & $0.60(0.25-1.46)$ & 0.264 \\
\hline Digital ulceration & $0.43(0.19-0.97)$ & 0.042 \\
\hline RNAP antibody & $2.91(1.05-8.21)$ & 0.044 \\
\hline Extended period on calcium channel blockers therapy & $1.09(0.50-2.36)$ & 0.830 \\
\hline & & \\
\hline Correlates of early cancer versus no cancer*** & OR (95\% CI) & \\
\hline Age at SSc onset* ${ }^{*}$ years & $1.05(1.03-1.08)$ & $<0.001$ \\
\hline Female & $1.51(0.56-4.13)$ & 0.418 \\
\hline Caucasian ethnicity & $1.25(0.36-4.31)$ & 0.726 \\
\hline
\end{tabular}




\begin{tabular}{|l|l|l|}
\hline History of smoking (current or previous) & $1.05(0.57-1.93)$ & 0.880 \\
\hline Extended period on immunosuppression^ & $0.62(0.31-1.24)$ & 0.180 \\
\hline Digital ulceration & $0.44(0.22-0.87)$ & 0.018 \\
\hline RNAP antibody & $2.14(1.03-4.45)$ & 0.043 \\
\hline
\end{tabular}

Abbreviations: systemic sclerosis (SSc), anticentromere (ACA), anti RNA Polymerase (RNAP) III

*SSc onset defined as the first symptom of SSc (Raynaud phenomenon or other)

**early cancer defined as diagnosed within five years of the onset of the first clinical manifestation of SSc (Raynaud phenomenon or other)

*** early cancer defined as diagnosed within five years of the onset of SSc skin changes compared with SSc patients without cancer with at least five years of disease duration since SSc onset (Raynaud phenomenon or other)

$\wedge$ Extended period on therapy (either CCB or immunosuppression) defined as $\geq 2$ consecutive years on therapy or $>50 \%$ of follow-up time in ASCS if follow-up time was $<2$ years

Exh on therapy (eiher CCB or imminosuppression) definod as $\geq 2$ conseculive years on therapy or $\geq 5 \% \%$ of follow-up time in AsCs if follow-up time was $<2$ years

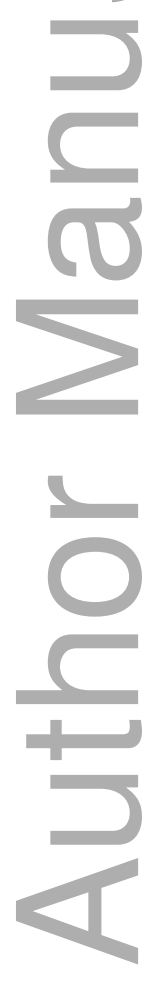


Table 5. Correlates of cancer types by multivariable logistic regression analysis

\begin{tabular}{|c|c|c|}
\hline Correlates of breast cancer $(n=74)$ & OR $(95 \% \mathrm{CI})$ & $P$ \\
\hline Age at SSc onset*, years & $1.03(1.01-1.05)$ & 0.005 \\
\hline Caucasian ethnicity & $1.57(0.48-5.12)$ & 0.457 \\
\hline History of smoking (current or previous) & $1.13(0.69-1.83)$ & 0.626 \\
\hline Extended period on immunosuppression ${ }^{\wedge}$ & $0.79(0.45-1.41)$ & 0.430 \\
\hline $\begin{array}{l}\text { Extended period on calcium channel blockers } \\
\text { therapy^}\end{array}$ & $1.61(0.99-2.63)$ & 0.051 \\
\hline Pregnancy history & $0.66(0.45-0.98)$ & 0.041 \\
\hline GIT manifestations & $2.99(1.07-8.36)$ & 0.036 \\
\hline \multicolumn{3}{|l|}{ Correlates of early breast cancer $(n=27)$} \\
\hline Age at SSc onset*, years & $1.07(1.03-1.11)$ & $<0.001$ \\
\hline Caucasian ethnicity & $1.69(0.22-13.3)$ & 0.617 \\
\hline History of smoking (current or previous) & $0.42(0.15-1.12)$ & 0.095 \\
\hline Limited disease subtype & $1.12(0.33-3.72)$ & 0.859 \\
\hline Extended period on immunosuppressive therapy^ ${ }^{\wedge}$ & $0.81(0.29-2.27)$ & 0.691 \\
\hline Pregnancy history & $0.87(0.39-1.92)$ & 0.727 \\
\hline Renal crisis & $2.36(0.45-12.3)$ & 0.309 \\
\hline RNAP antibody & $4.28(1.29-14.2)$ & 0.018 \\
\hline \multicolumn{3}{|l|}{ 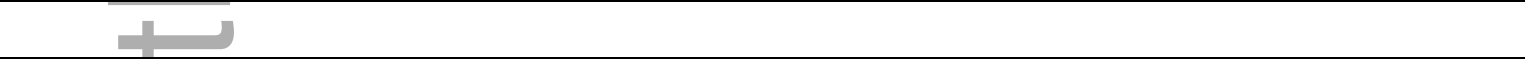 } \\
\hline Correlates of lung cancer $(n=25)$ & OR $(95 \% \mathrm{CI})$ & $P$ \\
\hline Age at SSc onset*, years & $1.01(0.97-1.03)$ & 0.810 \\
\hline Female & $2.08(0.57-7.51)$ & 0.266 \\
\hline White ethnicity & $1.04(0.23-4.69)$ & 0.960 \\
\hline
\end{tabular}




\begin{tabular}{|c|c|c|}
\hline History of smoking (current or previous) & $1.79(0.73-4.39)$ & 0.203 \\
\hline Extended period on mmunosuppressive therapy^ & $1.03(0.42-2.56)$ & 0.943 \\
\hline Anticentromere antibody (ACA) positive & $0.22(0.06-0.81)$ & 0.023 \\
\hline Interstitial lung disease (ILD) & $2.83(1.09-7.31)$ & 0.031 \\
\hline Pulmonary arterial hypertension (PAH) & $2.52(0.94-6.81)$ & 0.068 \\
\hline \multicolumn{3}{|l|}{ 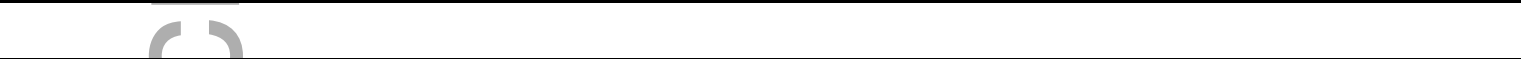 } \\
\hline Correlates of hematological cancer $(n=32)$ & OR $(95 \% \mathrm{CI})$ & $\boldsymbol{P}$ \\
\hline Age at SSc onset*, years & $1.04(1.01-1.07)$ & 0.007 \\
\hline Female & $0.79(0.31-2.03)$ & 0.622 \\
\hline History of smoking (current or previous) & $1.14(0.52-2.43)$ & 0.736 \\
\hline Extended period on immunosuppressive therapy ${ }^{\wedge}$ & $1.27(0.58-2.79)$ & 0.557 \\
\hline \multirow[t]{2}{*}{ SSc-specific antibody negative } & $0.35(0.16-0.73)$ & 0.005 \\
\hline & & \\
\hline Correlates of melanoma $(n=37)$ & OR $(95 \% \mathrm{CI})$ & $\boldsymbol{P}$ \\
\hline Age at SSc onset*, years & $1.01(0.99-1.03)$ & 0.428 \\
\hline Female & $0.69(0.28-1.73)$ & 0.432 \\
\hline History of smoking (current or previous) & $0.52(0.26-1.05)$ & 0.066 \\
\hline $\begin{array}{l}\text { Extended period on calcium channel blockers } \\
\text { therapy^ }\end{array}$ & $2.01(1.03-3.95)$ & 0.042 \\
\hline Extended period on immunosuppressive therapy ${ }^{\wedge}$ & $0.62(0.27-1.43)$ & 0.262 \\
\hline \multicolumn{3}{|l|}{ एक } \\
\hline \multicolumn{3}{|l|}{ Correlates of early melanoma $(n=11)$} \\
\hline Age at SSc onset*, years & $1.07(1.02-1.13)$ & 0.005 \\
\hline Female & $0.34(0.08-1.38)$ & 0.131 \\
\hline History of smoking (current or previous) & $0.48(0.13-1.75)$ & 0.266 \\
\hline Immunosuppressive therapy & $0.89(0.27-3.00)$ & 0.858 \\
\hline
\end{tabular}


*SSc onset defined as the first symptom of SSc (Raynaud phenomenon or other)

$\wedge$ Extended period on therapy defined as $\geq 2$ consecutive years on therapy or $\geq 50 \%$ of follow-up time in ASCS if follow-up time was $<2$ years

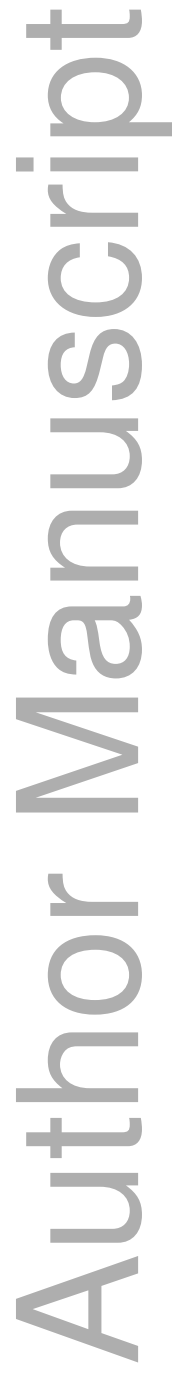

This article is protected by copyright. All rights reserved 
Table 6. Healthcare utilization and associated cost by cancer status (2008-2015)

\begin{tabular}{|c|c|c|c|}
\hline Episodes of care / total healthcare cost (AUD\$) & $\begin{array}{c}\text { Cancer } \\
\text { Median }\left(25^{\text {th }}-75^{\text {th }}\right)\end{array}$ & $\begin{array}{l}\text { No Cancer } \\
\text { Median }\left(25^{\text {th }}-75^{\text {th }}\right)\end{array}$ & $\begin{array}{c}\text { p- } \\
\text { value }\end{array}$ \\
\hline $\begin{array}{l}\text { Total healthcare cost per patient } 2008-2015 \\
\text { Average annual cost per patient consisting of: } \\
\text { average annual admission cost per patient } \\
\text { average annual ED presentation cost per patient } \\
\text { average annual MBS service cost per patient }\end{array}$ & $\begin{array}{c}52,798(32,172-103,516) \\
8,816(6,401-12,308) \\
4,196.6(2,676-6,489) \\
443(0-866) \\
3,164(2,173-5,825)\end{array}$ & $\begin{array}{c}35,810(16,467-35,810) \\
7,320(5,076-10,368) \\
3,776(2,291-5,928) \\
422(0-746) \\
2,319(1,380-3,502)\end{array}$ & $\begin{array}{c}<0.001 \\
<0.001 \\
0.050 \\
0.314 \\
<0.001\end{array}$ \\
\hline $\begin{array}{l}\text { Hospitalizations } \\
\text { Frequency of hospital visits per patient per annum } \\
\text { LOS per episode } \\
\text { Reason for hospital admission (top three) } \\
\end{array}$ & $\begin{array}{c}2.4(1-4.4) \\
1(1-2) \\
\text { Hemodialysis } \\
\text { Antineoplastic agent administration } \\
\text { SSc }\end{array}$ & $\begin{array}{c}1.7(1-3) \\
1(1-3) \\
\text { SSc } \\
\text { Iron deficiency anaemia } \\
\text { Cataract }\end{array}$ & $\begin{array}{l}0.001 \\
0.415\end{array}$ \\
\hline $\begin{array}{l}\text { ED presentations } \\
\text { Annual frequency of presentations per patient } \\
\text { Reason for ED presentation (top three) }\end{array}$ & $\begin{array}{l}\qquad 1(1-2) \\
\text { Chest pain } \\
\text { Intestinal obstruction } \\
\text { Acute LRTI }\end{array}$ & $\begin{array}{l}\text { 1 }(1-1.7) \\
\text { Chest pain } \\
\text { Intestinal obstruction } \\
\text { Dyspnoea }\end{array}$ & 0.247 \\
\hline $\begin{array}{l}\text { MBS utilization } \\
\text { Annual frequency of service utilization per patient } \\
\text { Services utilized (top three) }\end{array}$ & $\begin{array}{l}\qquad 88(57-144) \\
\text { Pathology }(42.1 \%) \\
\text { Professional attendances }(29.8 \%) \\
\text { Allied health services }(14.0 \%)\end{array}$ & $\begin{array}{l}\qquad 73(45-121) \\
\text { Pathology }(43.0 \%) \\
\text { Professional attendances }(30.2 \%) \\
\text { Allied health services }(14.2 \%)\end{array}$ & $<0.001$ \\
\hline
\end{tabular}

Abbreviations: standard deviation (SD), interquartile range (IQR). Medical Benefits Schedule (MBS), Emergency department (ED), length of stay (LOS), lower respiratory tract infection (LRTI),

scleroderma (SSc), All costs are in Australian Dollars (AUD) 
Figure 1(a) Survival in SSc patients with and without cancer in the ASCS prevalent cohort

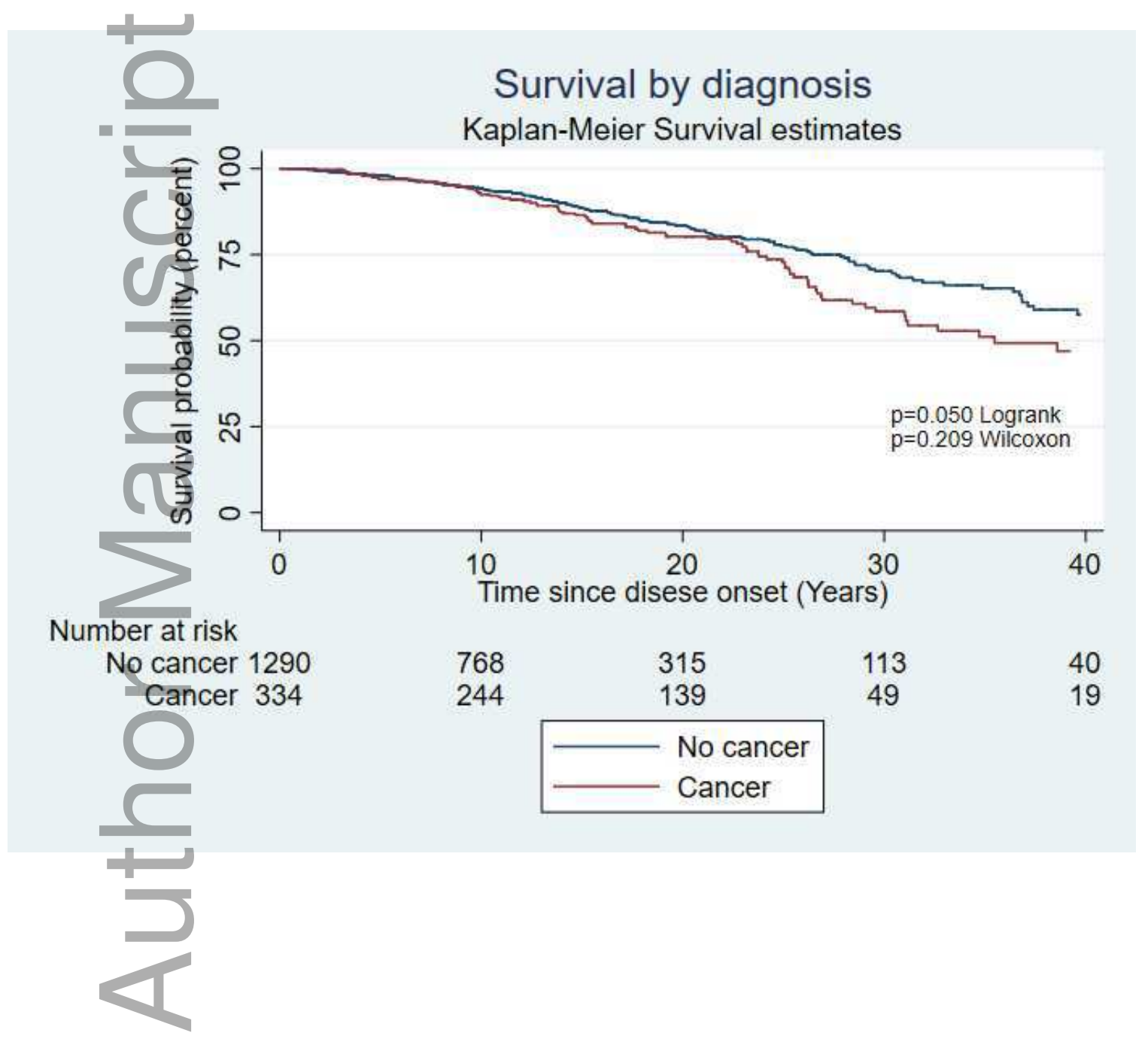

This article is protected by copyright. All rights reserved 
Figure 1(b) Survival of SSc patients with and without cancer in an incident cohort (defined as SSc patients enrolled in the ASCS within two years of SSc disease onset*)

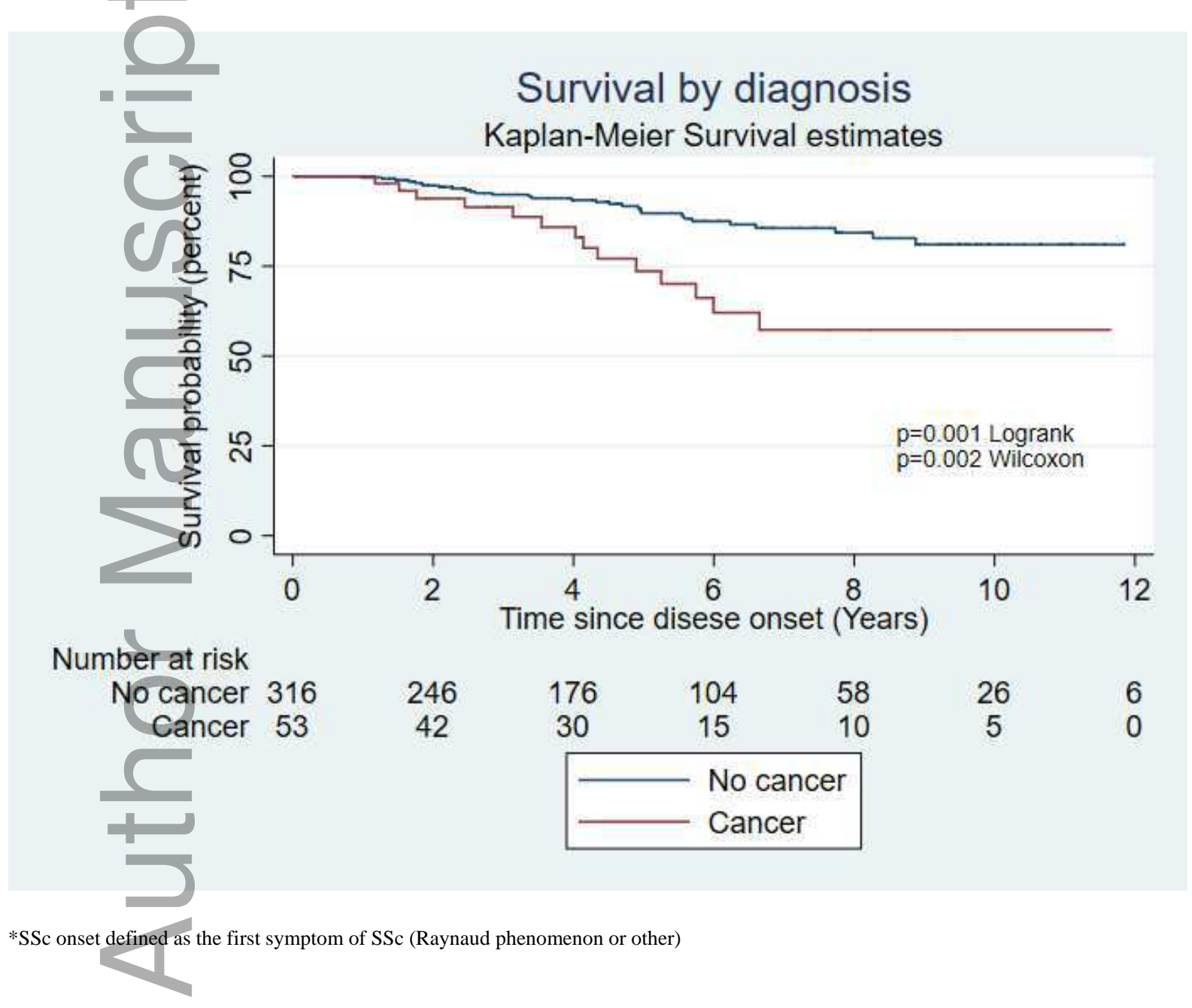

This article is protected by copyright. All rights reserved 


\section{University Library}

\section{- M M N E R VA A gateway to Melbourne's research publications}

Minerva Access is the Institutional Repository of The University of Melbourne

\section{Author/s:}

Morrisroe, K;Hansen, D;Huq, M;Stevens, W;Sahhar, J;Ngian, G-S;Ferdowsi, N;Hill, C;Roddy, J;Walker, J;Proudman, S;Nikpour, M

Title:

Incidence, Risk Factors, and Outcomes of Cancer in Systemic Sclerosis

Date:

2020-11-01

\section{Citation:}

Morrisroe, K., Hansen, D., Huq, M., Stevens, W., Sahhar, J., Ngian, G. -S., Ferdowsi, N., Hill, C., Roddy, J., Walker, J., Proudman, S. \& Nikpour, M. (2020). Incidence, Risk Factors, and Outcomes of Cancer in Systemic Sclerosis. ARTHRITIS CARE \& RESEARCH, 72 (11), pp.1625-1635. https://doi.org/10.1002/acr.24076.

Persistent Link:

http://hdl.handle.net/11343/276544 